\title{
Power Generation and Transmission Expansion Planning Procedures in Asia: Market Environment and Investment Problems
}

\subsection{Introduction}

This Chapter reviews the present status and prospective ideas of power generation and transmission planning procedures in a market environment. This problem is very important for different countries in Asia, as well as for other countries that have taken part in the liberalization of the electric power industry. Japan, Korea, China, India, Russia and others are now on the way of transition of their electric power industries to a new market structure and new economical conditions.

One of the main aims of electric power industry liberalization is the attraction of investment for new more effective generation and transmission development. The objective estimation of needed investment can be made on the basis of new advanced procedures of generation and transmission expansion planning in a market environment. This will be examined. There are many issues in the discussed problem. These include technology of power generation and transmission expansion planning procedures; methods of making decision on the generation and transmission network in a market environment; specific features of solving the discussed problem in different countries of the region; use of the correlation state regulation and market mechanisms for attraction of investment; and improvement of surplus generation for effective electricity market operation; etc.

\subsection{Problems of Electric Power System Expansion Planning in a Market Environment and Procedures of Their Solution}

In a liberalized environment different variants of the electric power industry structure are possible. These variants predetermine specific features of the problems of electric power system (EPS) expansion planning. In general this problem is solved by the rational combination of market mechanisms and state regulation, provided there are many subjects of relations (power supply companies, consumers, authorities, etc.) with a great number of commonly non-coincident criteria. And the uncertainty of future conditions for EPS expansion is responsible for a multi-variant character of possible decisions to be made and compared.

Complexity and multi-dimensionality of current extended EPSs, plurality of variants and criteria, availability of different preferences in decision choice all make it impossible to solve the EPS expansion problem as a general synthesis problem. In the centrally planned power industry this problem was solved by applying the hierarchical approach that was based primarily on the expert, but a posteriori technology of problem solution. In the liberalized 
power industry the problem is drastically complicated and the technology of its solution can be represented by different variants depending on specific features of the industry structure.

We will analyze different variants in structure of the power industry [1] that generate distinctions in the composition and character of EPS expansion planning problems. These variants comprise a regulated monopoly at all levels; interaction of vertically integrated EPS and open access to the main grid; a single buyer-seller of electricity (an electric network company) with competition of generating companies; competition of generating companies and a free choice of electricity supplier by selling companies or/and consumers when the main grid renders only transportation services; in addition to conditions of two previous cases (i) competition of selling companies in electricity supply to concrete consumers; (ii) intermediate and mixed variants based on the considered ones.

The general problem of EPS expansion planning can be divided into three groups of problems [2].

- The state strategies and programs for development of the power industry and EPS (the federal, interregional and regional levels);

- Strategic plans for development of power supply companies (vertically integrated, generating, network);

- Investment projects of electric power installations (power plants, substations, transmission lines).

In making decisions on EPS expansion different groups of subjects of relations have shown, largely non-coincident, interests that are expressed by the corresponding criteria. In particular:

1) Electricity producers or/and sellers (vertically integrated, generating or selling companies, an electric network company as the single buyer-seller of electricity) and also subjects of electric power industry rendering electric power services in the wholesale electricity market (maintenance of active and reactive power reserves, provision of system reliability, etc.) are interested in profit maximization as a result of their business.

2) Electricity consumers (selling companies of different levels, concrete consumers) are interested in minimization of the tariffs for electricity bought (in the wholesale or/and retail markets), provision of its quality and power supply reliability.

3) Interests of the authorities (federal and regional) are directed to maximization of payments into budgets of the corresponding levels, minimization of the environmental impact of electric power facilities, provision of the energy security of the country and regions, etc.

4) External investors (banks, juridical and natural persons) are interested in minimization of the period for return of investments in electric power installations, maximization of dividends, etc.

We will discuss the composition and specific features of EPS expansion planning problems from two points of view: technology and structure.

As to the technology an EPS is viewed as a technically single system consisting of power plants operating in parallel and connected with each other and consumers by an electric network. EPS can be modeled in different ways subject to the problem character and the level of consideration. For example, the structure and allocation of generating capacities of the 
Unified Electric Power System (UPS) of Russia are chosen as a rule on the base of aggregated representation of large subsystems (e.g. interconnected EPSs--IPSs) and transfer capabilities of tie lines among them. If the same problem is solved for IPSs, their structure is described similarly in the form of aggregated subsystems and transfer capabilities of tie lines between them. To plan network expansion it is necessary to represent it in detail with generation capacities and their allocation that are determined at the previous stages. The UPS level usually deals with the UHV backbone network. At the IPS level the electric network is represented in greater detail considering transmission lines, substations of lower voltage classes. This set of problems on EPS expansion planning is a hierarchical sequence of problems, where decisions on system expansion are adjusted (or new decisions are made) at each stage by means of more detailed examination in the technological and territorial aspects.

As to the structure the technically single EPS in decision-making on its expansion is a set of structural units, i.e. companies, interacting with each other. If the expansion problems are solved depending on the structure, an EPS should be represented by vertically integrated generating and network companies that will expand based on their technological interaction within the system. When choosing decisions on generation and transmission network expansion the vertically integrated company, for example, has to take into consideration potential decisions of neighboring companies on their expansion. The generating company has to allow for prospects in expansion of competing similar companies and the network company as well. The network company, in turn, should have an idea on expansion of generating companies when analyzing trends in its expansion.

Each generating company in this case should consider both prospects for expansion of other companies and the state energy policy (at the federal, interregional and regional levels) and mechanisms of its implementation in the form of tax, credit, tariff and other policies. On working out the strategies and programs of power industry development the state, in turn, should implement its energy policy by taking into account incentives, possible behavior and interaction of generating companies in their expansion.

In general the problems of EPS expansion planning as applied to many subjects of relations that are guided by many non-coincident criteria are of a multi-criteria game character. Let us examine specific features of such statements for the mentioned three groups of problems.

The state strategy and programs of power industry development at the federal and regional levels are elaborated commonly on the base of the hierarchical game multi-criteria statements of problems [3]. Such problems appear when the state is at the upper level and the power supply companies are at the lower level. These problems are solved by the formal methods for creating the incentives for subjects' behavior at the lower level by the appropriate mechanisms foreseen at the upper level.

Here the hierarchical game multi-criteria problems may be cooperative or non-cooperative depending on conditions.

These problems can take place at interaction of the federal and regional levels, when the state strategies and programs are elaborated for the power industry development. Such problems are aimed to coordinate interests of the country and its regions. The state priorities 
in the industry development are formed at the federal level and then they are transformed into concrete trends in expansion of generation capacities and electric networks in the considered region. In general when the principles of authority sharing are adjusted and noncontradictory, the hierarchical multi-criteria game problems of a cooperative nature can be involved. The mechanisms of inducement or persuasion are applicable here, however, with somewhat different conceptual interpretation as against the previous case.

The indicated two problems can be studied jointly as one problem that reflects interactions among three groups of subjects: federal and regional levels of the country and power supply companies. Such problems are considered, in particular, as active systems with the distributed control and also reduce to hierarchical game models.

In individual cases the simpler statements of the hierarchical two-level problem as a two-stage sequence of multi-criteria problems of mathematical programming can be used. The strategy of national power industry development is considered at the first stage, the appropriate recommendations are adjusted at the level of strategies of regional power industry development.

An analogous two-stage sequence of problems can be analyzed in intersectoral terms, when the basic proportions in power industry development are determined at the first stage by the territorial-production model of the fuel and energy complex. Then these proportions are adjusted on more detailed models for decision making on power industry development.

Main attention in the considered problems is paid to mechanisms of interaction between the federal and regional or the energy and sectoral levels of elaborating the state strategies and programs of power industry development. Therefore, consideration of incentives for the behavior of power supply companies by one or another technique for representing uncertain factors becomes necessary. The key task for power supply companies in this case is to work out effective economic, legal and institutional mechanisms. They are to stimulate the companies to take into account priorities of the state policy in the electric power industry when elaborating strategic plans of their expansion and making decisions on investment projects. The optimal proportions of such mechanisms can be improved by solving the hierarchical game problems for the subjects "state - power supply companies" mentioned above.

Now we will analyze the next group of problems dealing with elaboration of strategic plans of power supply company expansion. At least three classes of such problems can be discussed here.

For the regulated monopoly without competition it may turn out necessary to solve multi-criteria problems of mathematical programming in terms of uncertainty and different preferences [4]. A rather simple way for considering uncertain factors is a scenario representation of combinations of their values. The game problems in the class of "games with the nature" may be analyzed on the base of ordinary and fuzzy payoff matrices in the other cases.

Elaboration of the strategic plan of the network company expansion, when there are vertically integrated or purely generating companies, refers to the second class of problems. Considering, in a certain sense, a subordinate role of the network company that reduces in the most general case to provision of competition for power producers and a free choice for power 
consumers, the problems of network company expansion can be studied in terms of "games with the nature". In this case the uncertainty in behavior of both power producers and consumers in the wholesale market is essential and taken into account by the appropriate payoff matrix of the game. For the network company as the single buyer-seller of electricity the conceptual meaning of uncertain factors is determined, as before, by the competition and at the power consumption level it depends only on demand uncertainty and elasticity. However, here the problem can also be examined in terms of "games with nature".

The coordination between generating companies especially under state regulation is possible. The problem takes the form of cooperative game [5].

And finally, the third class of problems is related to elaboration of the strategic expansion plans of competing vertically integrated or purely generating companies. Without the state regulation the problem reduces to a multi-criteria non-cooperative game. With state regulation the problem takes the form of a multi-criteria cooperative game, probably of a multi-stage character, i.e. it reduces to a positional game [6,7].

The problems of the third group dealing with decision making on investment projects of electric power installations (power plants, substations, transmission lines) work out a business plan for construction of the corresponding installation. Mathematically the problem statement depends on the investor position. If the power supply company (e.g. the network company) invests in the installation, the investment project may call for multicriteria assessment. For an independent investor one should allow for an incentive for behavior of the other concerned subjects and the problem can be associated with the game statement. It can be either cooperative or non-cooperative depending on conditions.

\subsection{Proposed Performance Criteria for Transmission System Planning based on Regulating Framework of TWBP in Korea}

After the Korean Government unveiled "The Basic Plan for Restructuring of the Power Industry" in 1999, the Korean Electric Power Industry has been restructuring. Now, Cost Based Pool has been operated by KPX (Korea Power Exchange) from 2001, and market design of Two Way Bidding Pool is coming to the finish. As these circumstances change, power system planning is one of the most influenced parts by restructuring in the electric power industry in Korea. When the power system was operated by a vertically integrated utility; KEPCO (Korean Electric Power Company), planning was actually done by KEPCO on behalf of government, and the "long-term power development plan" has been made in accordance with the national electricity law. But, as Korean electric power industry has been restructured, various market participants already appeared and will appear in electricity market, so new regulating framework is established to guarantee the transparency of the electricity market, even though the Korean government decided to maintain government-leading resource planning even after restructuring of the electricity industry under the name of "electricity resource baseline plan" taking the demand/supply situation into consideration. Especially in the case of transmission system planning, it was discussed that objective and transparent criteria are required to be developed because a transmission company remains as a type of monopoly after restructuring in Korea, and the transmission network is strongly co-related to all market participants. Section 14.3 briefly reviews progress of restructuring in the Korean 
electric power industry, and examines the proposed regulating framework focusing on transmission network planning. In addition, Section 14.3 describes the proposed performance criteria for transmission system planning in Korea considering [8-12].

\subsubsection{The Progress of Reconstructing in Korea}

In "The Basic Plan for Restructuring of the Power Industry" unveiled by the Korean government in 1999, restructuring is scheduled as in the following steps (Figure 14.1).

\begin{tabular}{|c|}
\hline $\begin{array}{l}\text { Phase } 1(\sim 2002) \text { : Generation Competition } \\
\text { The generation sector of KEPCO was spilt up into six generation } \\
\text { subsidiaries, five of which are to be privatized step by step. } \\
\text { Gencos trade electricity by bidding through the Korea Power Exchange. }\end{array}$ \\
\hline Phase 2 (2003 2008) : Wholesale Competition \\
\hline $\begin{array}{l}\text { The Distribution/retail sector is to be separated from KEPCO into separate } \\
\text { companies, followed by the privatization of these companies as well. } \\
\text { The transmission network will remain open to all market participants } \\
\text { to ensure nondiscriminatory use of the national transmission network } \\
\text { Introduction of consumer choice for large consumers; small, } \\
\text { residential consumers will supplied by local distribution companies }\end{array}$ \\
\hline Phase 3 (2009 ) : Retail Competition \\
\hline $\begin{array}{l}\text { Every customer will be able to choose his or her own supplier of } \\
\text { electricity }\end{array}$ \\
\hline
\end{tabular}

Figure 14.1 The plan for restructuring of power industry

Now, the market design of a Two Way Bidding Pool for introducing wholesale competition and retail competition into the electricity market is coming to an end in Korea though some issues like the separation of the Distribution/retail sector from KEPCO are still under discussion. The following Tables are summaries of what has been achieved to date.

\subsubsection{Regulating Framework for Transmission System Planning}

As competition and deregulation are introduced into the Korean electric power industry, it has been discussed that the following is necessary to make better transmission planning under the new competitive environment that is facing uncertainties in the electricity market (Table 14.1).

- Establishing rational and objective planning standard

- Developing transparent transmission planning process

- Sharing sufficient information on transmission planning between market participants and planner

- Providing sufficient information on transmission expansion plan to market participants are necessary

- Improving efficiency on transmission investment by transmission planning:

(1) Designing incentive mechanism for efficient transmission planning by transmission planner

(2) Designing regulatory mechanism for transmission business 
Developments of the electricity network must be planned with sufficient lead time to allow any necessary statutory consents to be obtained and detailed engineering design/construction work to be completed.

\begin{tabular}{ll}
\hline \multicolumn{1}{c}{ Title } & \multicolumn{1}{c}{ Contents } \\
\hline $\begin{array}{l}\text { Grouping of Power } \\
\text { plants for Gencos. } \\
(1999,9)\end{array}$ & $\begin{array}{l}\text { Thermal plants were grouped into five GenCos in consideration } \\
\text { of balanced generating capacity revenue } \cdot \text { asset value. }\end{array}$ \\
& $\begin{array}{l}\text { Nuclear and Hydro plants were combined into one group in the } \\
\text { interest of ensuring safety and maintaining control of water } \\
\text { resources }\end{array}$ \\
$\begin{array}{ll}\text { Market Simulation } \\
(2000.4 \sim 2001.3)\end{array}$ & $\begin{array}{l}\text { One year of simulation prior to setting up the electricity trade } \\
\text { market and establishing the Korea Power Exchange }\end{array}$
\end{tabular}

Necessary Legislation , “ACT ON PROMOTION OF RESTRUCTURING OF THE Enacted. ELECTRIC POWER INDUSTRY" enacted on December 23, 2000 enables the separation of generation sector into several companies.

, "THE ELECTRICITY BUSINESS ACT" amended on Feb 24, 2002, mandates the establishment of an electricity trade market (Power Exchange) and a regulatory agency (Korea Electricity Commission)

Establishment of , Korean Power Exchange was established as a non-profit Korean Power independent organization, to facilitate transparent and fair Exchange (2001.4) management of the electricity trade market

Establishment of , Korea Electricity Commission manages the privatization process Korean Electricity and oversees market operation. It also takes necessary measures

Commission (2001.4) to protect consumers from unfair and deceptive business practices and to ensure fair competition among all participants

Establishment of Six , The six independent generation subsidiaries of KEPCO are

Generation

Companies (2001.4)

-Korea South-East Power Co. Ltd (KOSEPCO)

-Korea Midland Power Co. Ltd (KOMIPO)

-Korea Western Power Co. Ltd (KOWEPO)

-Korea Southern Power Co. Ltd (KOSPO)

-Korea East-West Power Co. Ltd (KEWESPO)

-Korea Hydro \& Nuclear Power Co. Ltd (KNHP)

Preparation for the , Five thermal power generation companies will be up for Privatization of GenCos privatization. Hydro and nuclear generation company is excluded from the plan.

, Plan consists of two stages of privatization

I Stage 1 : Beginning in 2002, two generation companies will be consecutively privatized.

I Stage 2 : After completion of stage 1 , the remaining three will be privatized(Process will begin no later than 2005)

Table 14.1. The Progress of Restructuring in Korea

The electric resources development plan (ERDP) and the business plan for transmission network development (BPTND) are documents that describe the actual and predicted future 
changes and additions to the electricity network. These documents show the opportunities for future connections and indicate those parts of the transmission network most suited to new connections and to the transport of further quantities of electricity. This will assist in encouraging the promotion of competition and the development of the transmission network in a non-discriminatory manner.

The network planning committee (NPC) is a key element in the transmission network planning process ensuring that the requirements and proposals of the Korea Electric Power Exchange (KPX), other network service providers (NSPs) and users will be fully considered.

\subsubsection{Network planning committee}

In order to facilitate detailed input into the preparation of the transmission network development plan and to provide a forum for co-ordination of this plan with all interested parties the Transmission Asset Owner (TAO) will establish and chair a transmission network planning committee (NPC). The NPC will provide an informal forum for considering detailed developments to the transmission network. Membership of the NPC will include the KPX, other NSPs and users of the transmission network.

The NPC will not have any decision-making functions and its role will be only advisory. The responsibility for planning the transmission network rests completely with the transmission asset owner.

\subsubsection{Business plan for transmission network development}

Annually the TAO will prepare and issue the detailed BPTND for the next seven years. The BPTND will use the output of the ERDP and will be produced within three month of the publication of the ERDP. The BPTND will consider all the requirements outlined in the ERDP from the needs identified by the various parties represented in the ERPC and will describe how those needs are being or will be incorporated within the plan.

The TAO will be responsible for the preparation of the final version of the BPTND but the TAO will consult with the KPX and will take into consideration the needs of the other parties involved. The final version of the BPTND shall be submitted to Ministry of Commerce, Industry and Energy (MOCIE) for approval.

Ultimately the TAO will be held accountable for the quality of the planning activities and planning results included in the BPTND. In the event of the KPX being unable to operate the system to the required standards as a direct result of a TAO decision not to make an investment, then the KPX will take the necessary operational measures to secure the system and protect electricity supplies. The TAO will meet any additional constraint costs that occur due to this.

The parties may conduct independent assessments to evaluate alternatives. The KPX may also identify and suggest needs for investment based on its operational experience, engineering practice and professional estimation.

The flowchart for the transmission network planning process is shown in Figure 14.2. 


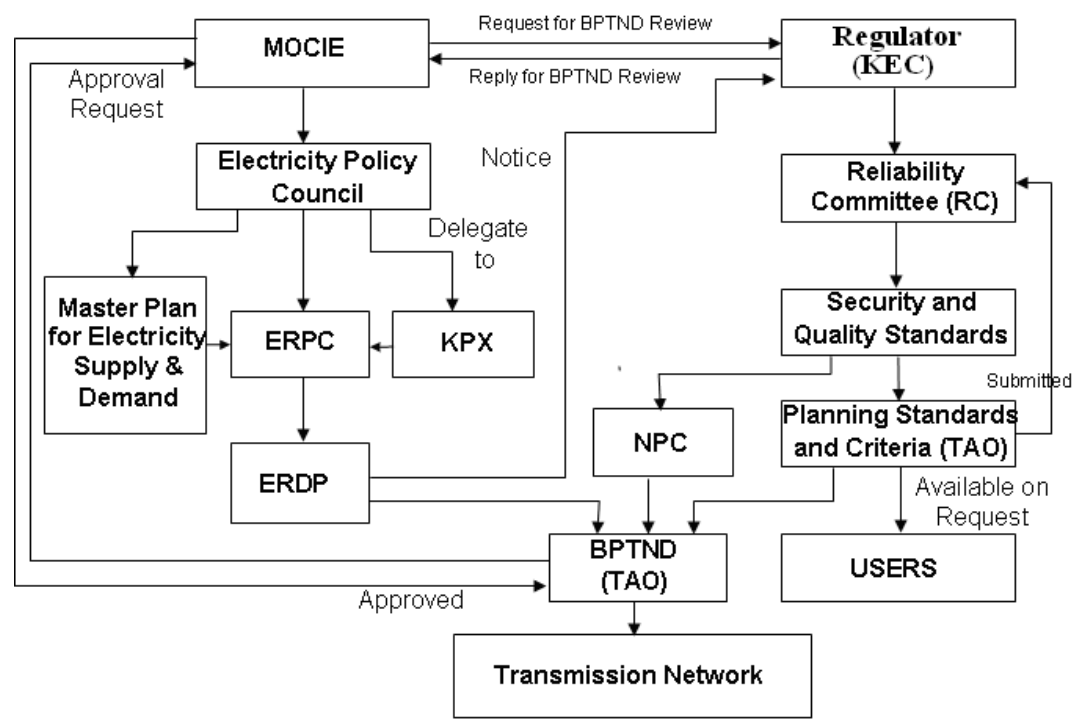

Figure 14.2. Transmission network planning flowchart

\subsubsection{Background to performance criteria for transmission system planning}

Based on the regulating framework for transmission system planning, this Section describes the proposed performance criteria as a part of planning standard and criteria.

\subsubsection{Development of performance criteria}

Performance criteria for transmission system planning is determined based on the extent that the transmission system can keep supplying electricity to loads when a disturbance occurs. However, load supplying may be interrupted by the adopted strategy of its system operator as well as by deterioration of electricity supplied. So, performance criteria should consider both aspects of these.

In Korea, the power system is operated at such a high reliability level that it never allows the loss of load on systems other than the one where a disturbance (including the failure of 1 route (2 circuits) $345 \mathrm{kV}$ line) occurs. Thus, in this Section, performance criteria for transmission system planning is proposed to assure this principle.

\subsubsection{Performance criteria for normal state}

Normal state is a state where all system elements are in service after the power system is adjusted to supply load following specified operating procedures, and no faults or outages occur. For this normal state, performance criteria should meet the normal operating criteria that the system operator would apply to power system operation. 


\subsubsection{Performance criteria for abnormal state}

\section{1) Classifying performance level}

Performance level is classified based on the allowable actions or conditions on systems other than the one where a disturbance occurs.

In this Section, considering the reliability criteria principle that is applied to Korean power system operation, any loss of load is not allowed in all performance levels. Table 14.2 shows each performance level classified by the allowable actions or conditions on system.

\begin{tabular}{|c|c|c|c|c|c|c|}
\hline Level Allowance & PA-1 & PPA-2 & PPA-3 & PPB-1 & PPB-2 & PPB-3 \\
\hline Tripping Generator & $\mathrm{NO}$ & $\mathrm{NO}$ & $\mathrm{NO}$ & YES & NO & YES \\
\hline $\begin{array}{l}\text { Generation Output } \\
\text { Adjustment }\end{array}$ & $\mathrm{NO}$ & YES & $\mathrm{NO}$ & $\mathrm{NO}$ & YES & YES \\
\hline $\begin{array}{l}\text { Temporary Loss of } \\
\text { Load* }\end{array}$ & NO & $\mathrm{NO}$ & YES & YES & YES & YES \\
\hline Loss of Load & $\mathrm{NO}$ & $\mathrm{NO}$ & $\mathrm{NO}$ & $\mathrm{NO}$ & $\mathrm{NO}$ & $\mathrm{NO}$ \\
\hline
\end{tabular}

*Temporary loss of load: Case of the dropped load being restored within a short period of the time by switching actions at the station where the load is supplied

Table 14.2. Performance Level

2) Classifying contingencies into performance level

Selections of the considered contingencies are based on probability of that contingency happening. Moreover, special considerations are given to the characteristics of the Korean Power system.

In general, contingencies have different effects on the power system according to importance of the transmission system where contingencies are occurred. Thus, in this criteria, the transmission system is divided according to its main function and its voltage level.

- Generator connection system : transmission facilities connected to connection point of generating unit.

- Main system : transmission facilities connecting generator connection system and load supplying system.

- Load supplying system: transmission facilities connected to connection point of load.

Table 14.3 shows contingency classification in each sectioned transmission system. 


\begin{tabular}{|c|c|c|c|c|c|c|}
\hline \multirow[t]{2}{*}{$\begin{array}{l}\text { Performance } \\
\text { level }\end{array}$} & \multicolumn{3}{|c|}{ Load supplying system $[\mathrm{kV}]$} & \multicolumn{3}{|c|}{ M. $\operatorname{Tr}[\mathrm{kV}]$} \\
\hline & 154 & & & 154 & 345 & 765 \\
\hline PA-1 & - & & & - & $\mathrm{O}$ & $\mathrm{O}$ \\
\hline PA-2 & $\mathrm{O}$ & & & - & - & - \\
\hline PA-3 & - & & & $\mathrm{O}$ & - & - \\
\hline PB-1 & $\mathrm{OO}$ & & & - & - & - \\
\hline PB-2 & - & & & - & - & - \\
\hline PB-3 & - & & & - & - & - \\
\hline \multirow{2}{*}{$\begin{array}{l}\text { Performance } \\
\text { level }\end{array}$} & \multicolumn{3}{|c|}{$\begin{array}{c}\text { Generator connection system } \\
{[\mathrm{kV}]}\end{array}$} & \multicolumn{3}{|c|}{ Core system $[\mathrm{kV}]$} \\
\hline & 154 & 345 & 765 & 154 & 345 & 765 \\
\hline PA-1 & $\mathrm{O}$ & $\mathrm{O}$ & - & - & - & - \\
\hline PA-2 & - & - & - & $\mathrm{O}$ & $\mathrm{O}$ & - \\
\hline PA-3 & - & - & - & - & - & - \\
\hline PB-1 & - & - & - & $\mathrm{OO}$ & - & - \\
\hline PB-2 & - & - & - & - & $\mathrm{OO}$ & $\mathrm{O}$ \\
\hline PB-3 & OO & OO & $\mathrm{O}$ & - & - & - \\
\hline
\end{tabular}

$\mathrm{O}$ : Failure of 1 circuit or 1 Transformer bank

OO: Failure of 1 route (both of 2 circuits) line

Table 14.3. Contingency Classification

\section{3) Transient voltage criteria}

a) Overvoltage

It was reported that over-voltage criteria is not required as a performance criteria [8], and is not recommended since it is usually related to a local problem

\section{b) Undervoltage}

Table 14.4 shows voltage dip criteria applied by WSCC to avoid uncontrolled loss of load [8]. In this table, the values were based on the estimated response of electronic equipment such as computers to voltage dips. In this Section, it is assumed that Korean electronic equipment has a similar characteristic at least, so the values of this table can be applied as an under-voltage criteria. But, only A and B steps in this table would be applied as a criteria since the Korean power system does not apermit any loss of load. 


\begin{tabular}{lccc}
\hline Step & $\begin{array}{c}\text { Instantaneous } \\
\text { Voltage } \\
\text { Drop }\end{array}$ & $\begin{array}{c}\text { Maximum Duration of Voltage } \\
\text { Dip Exceeding Minimum Drop }\end{array}$ & $\begin{array}{c}\text { Loss of } \\
\text { Load }\end{array}$ \\
\hline A & $25 \%$ & $20[$ cycle] & No \\
B & $30 \%$ & $20[$ cycle] & No \\
C & $30 \%$ & $40[$ cycle] & Critical \\
D & $30 \%$ & $60[$ cycle] & Yes \\
\hline
\end{tabular}

Table 14.4.Voltage Dip Criteria Comparing Loss of Load

4) Transient Frequency Criteria

a) Over Frequency

Over-frequency problem is mostly associated to generators, but generators usually have local protection. So, it is reported that over-frequency criteria is not recommended [8].

b) Underfrequency

Under-frequency criteria is selected to coordinate with the operational strategy for UFLS (under frequency load shedding). UFLS is expected to arrest frequency decline and avoid the cascading as a result of a disturbance.

To do this, UFLS relay is set to be coordinated with under-frequency protection of generators and any other actions planned to occur when the frequency drops.

In the Korean power system, the UFLS relay is set at $58.8 \mathrm{~Hz}$. According to this strategy, automatic load shedding starts if system frequency drops below this value. In this Section, low-frequency criteria is proposed not to allow any loss of load considering this UFLS strategy.

\section{5) Post transient voltage deviation}

The criteria for post transient voltage deviation is set to provide some measure of the ability of the system to recover to acceptable operating conditions following a disturbance. It is also known that this criteria can provide some information about the incipient voltage collapse problem though it is not sufficient as a voltage stability criteria. $5-10 \%$ deviation is usually recommended for this [8].

\subsubsection{Proposed Performance Criteria for Transmission System Planning}

\subsubsection{Performance criteria for a normal state}

A normal state should meet the following performance criteria considering the operating criteria of the Korean power system.

All transmission facilities should be kept within its thermal rating for normal state.

$\diamond$ System frequency should be usually at $60 \mathrm{~Hz}$, and adjusted within $60 \pm 0.2 \mathrm{~Hz}$ otherwise any exception occurs.

$\diamond$ Voltage in the transmission system should be kept within the following guidelines indicated in Table 14.5. 


\begin{tabular}{ccc}
\hline Voltage level & Voltage Criteria & Remarks \\
\hline $154 \mathrm{kV}$ & $156 \sim 164 \mathrm{kV}$ & Peak \\
& $152 \sim 160 \mathrm{kV}$ & Off-Peak \\
$345 \mathrm{kV}$ & $336 \sim 360 \mathrm{kV}$ & - \\
$765 \mathrm{kV}$ & $746 \sim 785 \mathrm{kV}$ & - \\
\hline
\end{tabular}

Table 14.5. Voltage Criteria for a Normal State

\subsubsection{Performance criteria for a disturbance}

A disturbance means a fault or outage of system elements that is not expected. Response of the transmission system to this has to meet its performance criteria. Table 14.6 shows the proposed performance criteria for each disturbance.

\begin{tabular}{|c|c|c|}
\hline $\begin{array}{l}\text { Performance } \\
\text { Level }\end{array}$ & $\begin{array}{c}\text { Transient Voltage Dip } \\
\text { (Measured in a Load Bus) }\end{array}$ & $\begin{array}{c}\text { Transient Frequency } \\
\text { (Measured in a Load Bus) }\end{array}$ \\
\hline PA-1 & $\begin{array}{l}\text {-Maximum voltage dip : } 25 \% \\
\text {-Max. Duration of V dip } \\
\text { exceeding } \\
20 \%: 20 \text { cycle }\end{array}$ & $\begin{array}{l}\text {-Minimum : } 59.6 \mathrm{~Hz} \\
\text {-Max. duration of } \mathrm{F} \text { below } \\
\text { Min : 6cycle }\end{array}$ \\
\hline PA-2 & Same as above & Same as above \\
\hline PA-3 & Same as above & Same as above \\
\hline PB-1 & $\begin{array}{l}\text {-Maximum voltage dip : } 30 \% \\
\text {-Max. Duration of V dip } \\
\text { exceeding } \\
20 \%: 30 \text { cycle }\end{array}$ & $\begin{array}{l}\text {-Minimum : } 58.9 \mathrm{~Hz} \\
\text {-Max. duration of } \mathrm{F} \text { below } \\
\text { Min : 6cycle }\end{array}$ \\
\hline PB-2 & Same as above & Same as above \\
\hline PB-3 & Same as above & Same as above \\
\hline $\begin{array}{c}\text { Performance } \\
\text { Level }\end{array}$ & $\begin{array}{c}\text { Post } \\
\text { Transient } \\
\text { Deviation } \\
\end{array}$ & Loading \\
\hline PA-1 & Positive & Within nominated rating \\
\hline PA-2 & Positive & Within emergency rating \\
\hline PA-3 & Positive & Same as above \\
\hline PB-1 & Positive & Same as above \\
\hline PB-2 & Positive & Same as above \\
\hline PB-3 & Positive & Same as above \\
\hline
\end{tabular}

Table 14.6. Performance Criteria for a Disturbance

Thus, as the electric power industry undergoes restructuring in Korea, it has been discussed that a reasonable regulation for guiding planning needs to be established, and the objective and rational criteria for transmission planning needs to be developed because a transmission company still remains as a type of monopoly after restructuring in Korea, and investment into the transmission system should be considered fairly and transparently. A transmission system determines a kind of infrastructure for trading electricity in the electric power market, so we 
have to promote transparent and rational circumstances to induce efficient investment. This Section reviews the progress of restructuring in the Korean electric power industry, and describes a regulating framework for transmission system planning. In addition, this Section examines the proposed criteria for transmission system planning. The proposed regulating frameworks provide various market participants with many chances to correlate them in planning the transmission system, and the proposed performance criteria became an objective standard by which transmission system is planned and maintained in the electricity market.

\subsection{Power Generation and Transmission Planning in India - Methodology, Problems and Investments}

India starting from an overall installed capacity of little above 1,300 MW at the time of its independence in the late nineteen forties, through its successive five-year planning periods could achieve a level of about 110,000 MW with energy generation of the order of 600 billion units in five and half decades. Though initial generation was concentrated to meet load in urban areas, at present vast countryside too has been covered under a massive electrification program.

Due to thrust on hydro development for the purpose of both irrigation and power, the nineteen fifties and sixties saw a good hydro-thermal mix in the generation front to meet the load along with the formation of Electricity Boards under the State Governments of the Republic of India and some river-valley project authorities for the implementation of projects. Due to the low level of load and the shorter distance of haulage of power, grids hitherto had been restricted to $132 \mathrm{kV}$ and seldom going up to the $220 \mathrm{kV}$ level. But with the setting up of quite a good number of mine-mouth large thermal power stations and few hydro power stations at the regional level by the Central Government-owned Companies starting from the 1980s, state grids were integrated to form the regional ones with simultaneous development of $400 \mathrm{kV}$ networks for power evacuation from major stations as well as for strengthening of networks. Thus came into existence the five regional grids in the Northern, Western, Southern, Eastern and Northeastern part of the country. At present out of these further integration has made it possible to connect the Northeastern, Eastern and Western systems synchronously. The other two continue to operate through asynchronous mode of interconnection (HVDC) with the combined one, both in the form of back-to-back and bulk supply links.

In the mean time with restructuring vis-à-vis reform taking place in the power sector from the early nineties, some Independent Power Producers (IPPs) came into the arena and started feeding to the state grids coming under the concerned regional grid. At the same time in order to improve efficiency and performance in general in certain states vertically integrated state utilities were unbundled to form generation, transmission and distribution companies. Though the transmission sector was opened up for private sector participation in early 1998, it is yet to pick up. As traditionally in pockets, generation and distribution activities existed in the private sector, only these saw further expansion through setting up of new generation plants and acquisition of distribution companies. Transmission as a natural monopoly remains still under government-owned companies, both at central and state level, though at the beginning of 1998 it has been opened to private enterprises to build, own and operate from point to point. With the open access in inter-state transmission to any distribution company, trader, generating company, captive plant or any permitted consumer as per recent order of Central Electricity Regulatory Commission (CERC) certain changes are, however, expected in future. 
With the Central Electricity Authority (CEA) of the Ministry of Power of the Government of India at the helm of affairs, the basic work of planning starts with load survey. State Electricity Boards (SEBs) at the grass-root level do the spadework with different agencies involved through collection of data concerning new demand in commercial, industrial, domestic, public service and irrigation areas and also growth for the existing systems in corresponding areas. CEA consolidates the projected figures on an all-India basis by working in close coordination with the SEBs and forecasts load and work out total requirement of electric energy and peak load to be met for the next few five-year plan periods based on a combination of partial end use technique and trend analysis, and computing long term projection by extrapolating the energy requirement at power station busbar. Various components, such as, Transmission and Distribution (T \& D) losses (both technical and commercial), load factor, diversity factor, etc. are also taken into account state / system-wise along with growth rate. As the National Power Grid is under formation, long-term projection takes care of regional diversity factor considering the significant daylight time difference across the country from east to west. Recession in economy, restructuring of SEBs are the other pertinent factors that influence the overall scenario. These figures are, however, scrutinized by certain Departments of the Government of India including the Planning Commission keeping in mind the commensurate fund requirement vis-à-vis relative priority with respect to the other sectors of infrastructure of the country for investment under public sector.

Having made the blue print, CEA further works out the details of generation corresponding to various scenarios of load projected for a few five-year plans ahead. In the last two decades in order to boost the economy, for rapid addition to generation, setting up of thermal generation plants was given much preference. Though side-by-side hydroelectric power stations were added, the balance tilted very much in favor of thermal to push it to the level of about $72 \%$ of the total capacity installed. This is primarily on account of the long gestation period, as a result of rehabilitation and resettlement, and other environmental problems, the inter-state riverwater dispute, etc. and consequent cost and time overrun. Of late more attention is being paid to this type of generation of electric power to strike a balance, which is needed for proper grid operation efficiently with standard parameters and in the most economic way.

With opening of the trade barrier, alternatives are also being looked at, like, whether to import fossil fuel or to produce indigenously. Exploration of new gas-wells as well as offshore drilling has lead to quick addition of gas-based plants, which of late are coming up and added to the grid with combined-cycle mode of operation. Thus under integrated resource planning, considering all possible sources to produce electricity in conventional ways including the nuclear one, most optimum solution is attempted for meeting the load requirement. In the process of planning for addition of generation, issues of system improvement to minimize $\mathrm{T} \&$ D losses, raising of plant load factor, Renovation and Modernization ( $R$ \& $M$ ) of old but still running power plants and also generation from renewable and non-conventional sources, etc. are considered to augment overall supply. Having known the load points, in the process it identifies the possible corridors of transmission of power vis-à-vis energy, though voltage level for it may be just an indicative one at this stage.

As applicable for the planning of any system, the basic philosophy of configuring transmission system is to achieve a level of operating performance with adequacy and security, which in 
turn requires a trade-off between cost and risk. It may be based on either a deterministic or a probabilistic approach. Though with an enormous amount of operational data available vis-àvis past experience latter mode may be adopted for investing further, in the scenario of rapid development of system one may have to bank upon still on a deterministic approach very much or on a combination of both to expect ultimately acceptable system performance. Accordingly certain planning criteria have been evolved in India. Inputs in the form of possible generation sites with capacity available and so the loads in bulk, the process of transmission planning starts. It involves not only the corridors of transmission lines with voltage levels but also with the finding of locations of associated substations. Adequate transformation capacity in the substation with the possibility of future expansion, flexibility at the operation stage, etc. is the major guiding factors for such planning exercises. The systems so planned, hitherto on a regional basis are then presented in Standing Committee of the concerned region. Decision is taken to firm up the addition with the identification of agencies in the Central and State sector responsible for construction, owning and operation.

The problems encountered in having the feasibility of generation especially for hydro development is enormous. In the southern part of the country, while harnessing has been quite appreciable, most of the new generations from this type of source are expected further in the Himalayan region in the northern and northeastern part of the country. Besides rehabilitation and resettlement problem, issues concerning geological stability of the areas as well as consequent transportation of equipment and transmission of power to load centers pose great challenges.

Though in thermal generation expansion, the problem is somewhat less, indigenously available coal has high ash content resulting in somewhat unusually oversized designing of boiler and associated plants for large thermal sets. Of course with economy of scale not so an important factor, IPPs have come up with various sizes of units of different smaller sizes. But in the long run maintainability of equipment may require larger investment on account of spares. But due to high rate of growth in load, as inevitable for any developing country, in a shorter time frame, it is also highly desirable to add to the system larger units, particularly when solid fuel is used, to have quicker enhancement of installed capacity. However, this is being limited to some extent due to high-ash contained indigenous coal for use in thermal generation, as just mentioned.

On the other hand due to large population and environmental restrictions particularly due to forest coverage, Right-Of-Way (ROW) for the construction of Extra High Voltage (EHV) transmission lines is gradually becoming more and more difficult. In the early nineteen eighties due to the construction of single-circuit $400 \mathrm{kV}$ lines quite a good amount of corridors have been lost with limited amount of flow of power. In fact subsequently with almost same amount of corridor width double circuit construction in hexagonal formation has paved the way for haulage of twice the amount of power. However, as a measure of enhancement of power flow, series compensation (both static and dynamic) is being implemented to increase loading capability of these lines. Also with the development of loads at intermediate locations, hitherto operating long lines (above $400 \mathrm{~km}$ ) are being broken to form new substations in between, thereby improving structural stability and other operating parameters of the system in addition to enhancement of loading through these lines. Similarly on certain corridors 
through forest multi-voltage multi-circuit transmission is being attempted. But still some bottlenecks may be existing in the transmission system on account of inadequate compensation of reactive power at lower voltages, leading to burdening EHV system to run at lower voltage and consequently unable to deliver active power of the desired level. However, through various measures being attempted, the situation is improving.

On the investment front, if one looks right from independence it may be seen that the whole power sector has been primarily nurtured with funding by the state. Very little investment has come through private sources that concentrated in and around some of the large metropolitan cities. Only since the early nineties have the latter channels become active with opening up of the sector. Though transmission is yet to pick up, for generation and distribution, some progress has been made. The issue of cross-subsidy for the domestic and agricultural areas through revenue earning from commercial and industrial areas could not produce enough revenue on net basis for future investment, resulting in poor financial health of power utilities of the states. Due to this background, it failed to attract private investment even when high rate of return was permitted. Under this category whatever investment has been made so far in generation, it is restricted to thermal (mostly gas or liquid fuel based), barring one or two hydro projects.

In the power sector, like any other physical system, overall efficiency, is a point to be reckoned with. This naturally gives importance to the distribution system too. After giving due attention to generation in the initial stages, followed by the transmission system by making it sure to link with every generating system coming up, now the distribution system is being revamped under an accelerated development program with the public investment to a large extent through the states. Haphazard growth due to compelling requirement of delivering electricity to every place at the cost of deteriorating parameters resulted in a system with high losses, which when accompanied by low collection of revenue lead to almost bankruptcy of suppliers, mostly the public sector power utilities. To some extent it leads private investors too to shy away from the scene of running the distribution systems. However, with the concept of individual center of profit introduced to some extent, the situation is gradually improving with additional investment pouring in this vital part of the power sector.

\subsection{Power System And Power Market Development In China Problems And Proposed Alliviation Measures}

The economy of China developed at a quite fast rate with an average of $9.5 \%$ increase of GDP from 1978 to 2000. Most of the time, the power industry was under pressure of the capacity shortage. Only in recent years (especially 1997-1999) most power systems experienced capacity adequacy. Generally speaking, in years of 2000-2002 the demand and supply in China were almost balanced, except in some minor parts of power systems. However, starting from the summer of 2003, 21 provincial power systems experienced energy shortage, the situation has been getting worse during the winter. In 2003 the yearly installed generation capacity (including thermal, hydro and nuclear) was 30,000 MW, it is the fastest rate in the world; however, the rate of power consumption was still faster, it reached $15.3 \%$ in 2003. In 2004 37,000 MW of generation capacity was installed, still more was added in 2005 and 2006. The energy shortage problem was probably alleviated from 2005/2006. 
The total installed generation capacity by the end of 2003 reached 384.5 GW, total yearly consumption reached 1,908 TWh, both numbered second place in the world.

The yearly total installed generation capacity in China from 1952 till 2020 is shown in Figure 14.3. Nationwide interconnection of regional power systems in China in 2005 is shown in Figure 14.4.

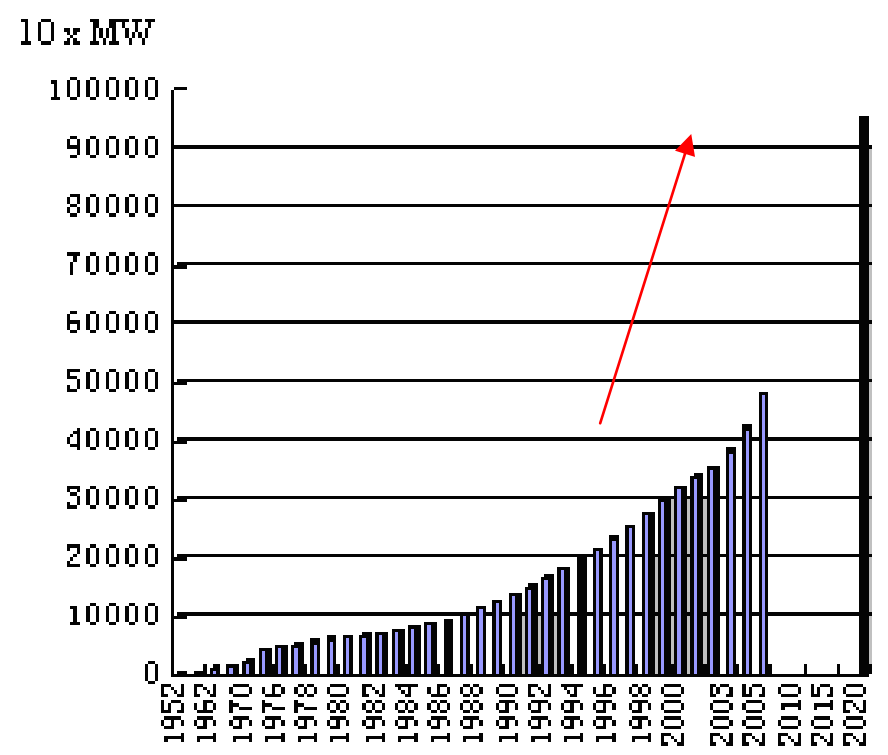

Figure 14.3. Yearly total installed capacity in China

The rate of installation of transmission lines has been very fast too. The total length of 220 $\mathrm{kV}$ and above transmission lines by the end of 2002 reached 188,700 km, in which 37,000 are $500 \mathrm{kV}$ lines. At present there are six large regional power systems and 5 provincial power systems (usually they are not interconnected with the main grid). By the end of 2005 these power systems in China were interconnected into a huge nationwide power network linked by $500 \mathrm{kV}$ and $750 \mathrm{kV} \mathrm{HVAC/HVDC}$ transmission lines except Xinjiang and Xizang autonomous region and Taiwan. This would further alleviate the energy shortage problem.

Considering the changing status for power shortage and power surplus, some key issues related to power systems security and generation capacity adequacy are discussed. One important issue is how to coordinate system generation and power grid construction under the environment of the power market with separated generation and transmission companies. Another issue is about how to setup power markets under the situation of continuously changing status of system generation capacity adequacy. In order to manage the generation adequacy problem, the basic conditions for the opening of a market and the requirement for market normal operation criterions are also discussed.

Along with the introduction of nationwide power systems interconnection and power market development, the most important issues are how to improve procedures for generation 
planning and transmission expansion planning, how to procure investment for building new power plants and new transmission lines, and how to alleviate energy shortage problems under a deregulation environment. These problems are discussed below $[13,14]$.

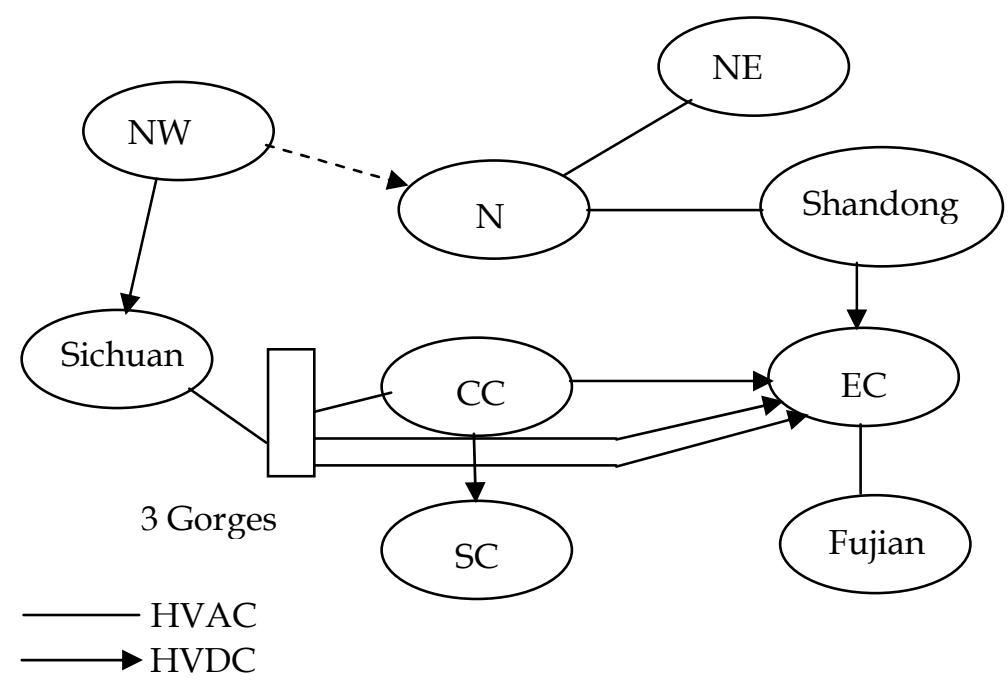

Figure 14.4. Nationwide interconnection of power systems in 2005 of China

\subsubsection{Power Market Development}

Since the first implementation of deregulation of the power sector in UK in 1990, more than 38 power systems in the world has restructured their power system and introduced competition in their electricity markets. There has been a lot of experience and lessons learned during their implementation, however, the restructuring of each later electricity market has benefited from the experience and failures of former electricity markets.

China has implemented her experimental electricity markets during 1999-2000. Six provincial/municipal power systems have been restructured to implement the electricity market, i.e. Shandong, Zhejiang, Shanghai, Liaoning, Heilongjiang and Jilin. Their experiences are:

- Ownership of power plants were not privatized, they were still owned by the state government or provincial government or foreign and domestic investors, but they were separated from the grid company and become independent power plants (IPP).

- About $80-90 \%$ of the demand are long-term bilateral contracts (usually one year) between IPPs and the grid company, the rest (10-20\%) of the demand is under competition. This practice guarantees stable supply of energy to the user.

- They all established their power market support systems (including dedicated communication links, information system, bidding management system, schedule 
application software, settlement management system), they were all developed by different Chinese vendors.

- The power systems have been in operation successfully and improved the efficiency of IPPs. Since the price of users cannot change, so the grid companies have gained some revenues through competition.

However, there are some limitations of deregulation at the provincial level, because deregulation at the provincial level can only optimize the utilization of resources in their own territory, they are not able to optimize the utilization of resource in the whole region, even when there are cheaper, cleaner energy in neighboring provinces. So what should we do next? Shall we continue to establish an electricity market in each province, or shall we establish an electricity market on a larger scale?

After evaluation of experiences of deregulation in China and abroad, the State Government of China made a decision in 2002 for restructuring of the power industry: The former State Power Company would be broken into five large generation companies (Huaneng Group, Huadian, Guodian, Datang, Power Investment), and two grid companies (State Grid Company-SG, South China Grid Company-SCG). There are five regional grid companies under the SG (NE China, North China, NW China, Central China, East China) and five provincial grid companies under the SCG in southern part of China (Guangdong, Guangxi, Yunnan, Guizhou and Hainan). The National Electric Power Regulation Commission (NEPRC) was established to monitor and regulate the forming and operation of six regional power markets. The forming of five generation companies and six regional grid companies including the SGC was completed by end of 2003.

According to the new policy, each regional grid company should establish one or several dispatch and trading centers (DTC) in their region. How can we establish regional power markets under the present energy shortage condition?

Fortunately not all regions and provinces has energy shortage problems, for example, the NE regional power system has no shortage problem, they are the first to establish their regional power market. After serious planning and design, their power market support system has been in trial operation since the middle of January 2004. Their special features are as follows:

- The regional DTC is responsible for all wholesale trading and dispatch of $500 \mathrm{kV}$ transmission lines in their region. Provincial dispatch centers are responsible for the security of operation and retail trading in their provinces.

- The regional DTC begin to collect transmission service charges for $500 \mathrm{kV}$ transmission lines.

- The regional DTC is responsible for the yearly generation market (consists of about $80 \%$ of the yearly demand forecast), monthly market (about $20 \%$ of the remaining demand forecast), and a day-ahead market for competition, a real time balancing market, and ancillary services.

- A two-part tariff system is implemented for IPPs, which include a capacity charge and an operation charge. The capacity charge would be paid to all available generators no matter whether it is dispatched or not, to compensate their equipment and installation cost. 
The operation cost would be only paid to those generators whose bidding price is lower than or equal to the system marginal price.

- Other functions are similar to former provincial power markets.

- East China Regional Grid Company was the second regional power market; it was in trial operation in June 2004. Their special features are as follows:

- Provincial DTCs will coexist with regional DTC.

- The regional DTC will be responsible for day-ahead market and real-time market, provincial DTC will be responsible for long-term bilateral contracts (mostly one year contract between provincial DTC and IPPs in their provinces) and ancillary services.

- The regional DTC will be responsible for coordination between provincial DTCs.

- Other functions are similar to NE regional DTC.

The type of other regional markets will be similar to either NE China or East China. They are all actively planning and the design stage, and were in trial operation from 2005-2006.

There is a National Control Center in China; their future mission is coordination among six regional power markets, and settlement of $500 \mathrm{kV}$ and above tie-line charges between regions.

\subsubsection{Generation Planning, Transmission Expansion Planning and Investment in China}

Generation planning. In the past, electric power design institutes usually undertook generation planning and transmission expansion planning studies. Take a regional power system for example. The usual way is, the regional grid company (RGC) provides the load forecast (5 years or 10 years), and entrust a design institute (usually a large design institute in the same region) to do the generation planning and transmission expansion planning. Based on the load forecast, the entrusted design institute would make a study on how much generation capacity will be needed each year, where these generation plants should be located, how many transmissions corridors would be needed to transmit the power to the load. The design institute would propose several schemes, make technical and economic studies and compare the results. The regional grid company and State Grid Company approves the final plan. Sometimes some very important planning projects (such as Three Gorges transmission project) can be entrusted to CEPRI to do detailed analysis, because CEPRI has advanced analytical tools and experienced experts.

If there are hydro resources available in the region, hydro generation planning would be entrusted to hydroelectric power survey and design institutes. They will make a survey on the water resources in the region, and make a proposal on the location and capacity of hydro stations to be built, and a yearly construction schedule. This proposal will be submitted to the regional grid company and Ministry of Water Resources as well as to the State Grid Company for approval. If it were a 5-year plan or 10-year plan, the hydro generation plan would be updated every year.

Transmission expansion planning. Usually regional grid companies are responsible for transmission planning between provinces (usually $500 \mathrm{kV}$ or above); provincial power companies are responsible for transmission planning in their provinces (usually $220 \mathrm{kV}$ ). There are six large thermal power design institutes and six hydro-electric power design and survey institutes, one in each region, and small design institutes in each province, they do 
the planning works for the regional grid companies. For very large transmission projects (such as Three Gorges transmission project or Nationwide Interconnection Transmission Project), many design institutes, together with the General Electric Power Planning and Design Institute (GEPPDI) and China Electric Power Research Institute (CEPRI) are working together to do the planning. Based on local load forecast and the national economic growth rate, and generation planning in the whole region, they would work out several transmission schemes, such as pure AC or DC, or hybrid AC/DC, what voltage level should be adopted, etc. for each scheme, technical and economical analysis will be made, such as load flow analysis, n-1 security analysis, transient stability analysis and dynamic stability analysis, sub-synchronous analysis etc. By comparison of technical and economical results of several feasible schemes, the best scheme will be determined. Again, the final transmissionplanning proposal will be approved by the State Grid Company (former State Power Company).

After deregulation, the generation and transmission expansion planning procedure may not change much.

Investment. As for investment, in the past practically most of the power plants and transmission construction were funded by the former State Power or former Ministry of Power, except some large industry owned power plants. Since the national budget was limited, so the investment problem has been a limiting factor for the growth of generation and transmission expansion in China. To overcome the energy shortage problem, in the mid nineteen eighties the "provinces take the main role" policy prevails, some were invested by local banks, some by foreign loans, and some BOT plants were built. Before the separation of generation and transmission, the former SP manages state-owned electric power assets (almost half of the generating capacity) and ran the country's national transmission networks. After reform, the ownership of power plants is distributed to five large generation companies. They take responsibility to invest in new power plants. They have income from operating their IPPs, if necessary they may obtain loans from local or foreign banks. As for which generation company may obtain the right to build new plants for a certain regional company, there are two possible options: by bidding, or by contract.

The investment for new transmission lines came from various sources. Usually the investment for tie lines ( $330 \mathrm{kV}$ and above) between provinces was shared by provincial power companies. Investment for transmission lines (500 kV AC/DC) between two large regions usually was shared by the two neighboring regional grid companies. Investment for outgoing lines connecting the power plant to the main grid was usually included in the budget of the power plant project. For very large power plant or transmission project such as Three Gorges project, the state government provides the investment; the National Congress approved it. We assume that the source of investment for new transmission line projects may continue to be so after the reform.

\subsubsection{Energy shortage problems and proposed alleviation measures}

In the introduction it is mentioned that China faced serious energy shortage problem in 2003. Twenty one provinces had to partly curtail their load which caused considerable damage to 
the industry and inconvenience to social life. The cause of energy shortage is due to the following reasons:

The rate of economic growth was faster than it was expected. The rate of economic growth for 2003 was planned at $7 \%$, but the actual growth rate reached $9.1 \%$, and the annual consumption of energy increased $15.3 \%$. Of course energy shortage became inevitable.

There was drought in some of the provinces; consequently hydro-stations cannot produce enough power, which only make the energy shortage problem worse.

Although China produced 1.7 billion ton of coal in 2003, China still cannot provide enough coal for thermal power plants. This was another cause of the energy shortage.

\subsubsection{The proposed counter measures}

1) To increase annual installed generation capacity. China installed $37,000 \mathrm{MW}$ of generation in 2004 and 48,000 MW in 2005 [1]. It seems that the investment was not a problem, because most provinces which suffered from energy shortage were very enthusiastic to invest and install new power plants in their provinces. The energy shortage problem became alleviated in 2005-2006.

2) To increase the reserve capacity requirement. According to the present design guideline, the requirement for reserve capacity is between $20-30 \%$ (including $8-15 \%$ for maintenance schedule); usually $25 \%$ reserve is used for planning purpose. Since the long-term load growth rate is difficult to predict accurately especially in a fast growing environment like China, it is recommended to use a higher figure for planning purposes to avoid future energy shortages.

3) More reserve capacity may result in a large number of power plants to become idle if the rate of load growth is slower than predicted. However, in China, a two-part tariff system in power market bidding was adopted. One part is capacity cost, which just cover the average cost of investment per $\mathrm{kW}$ of power plant no matter whether the generator is dispatched or not. The other part is bidding price, it depends on the efficiency of operation of the generator. A two-part pricing scheme is already being experimented with in the NE China Power Market. By application of this two-part tariff system the risk of investors for building new power plants can be considerably reduced.

4) To limit investment for new fast growing, energy intensive and low efficient industries. The state government has made a decision to limit new investment for steel, electrolytic aluminum, and the cement industries and construction of more luxurious houses. If the original schedule for installing steel plants was completed in end 2005, the yearly production capacity of steel in China would reach 330 million ton, it would be far more than necessary. The production capacity of electrolytic aluminum, and the cement industries are in a similar situation, if not worse.

5) To shave peak load, in East China and South China a two-stage energy tariff system has been implemented. It is likely more regions will adopt this system.

6) Demand Side Management (DSM). This technology has been implemented in Shanghai and other cities. A multi-stage energy tariff system is applied for some industries. It implies 
that the higher the load, the higher the energy tariff, which automatically encourages the user to reduce their own load. This measure is very effective to help reduce the load; experience in Shanghai has led in a reduction of 2,000 MW in peak load.

7) Likewise, the average unit production cost per energy consumption is high in China, about $0.15 \mathrm{kWh} / \mathrm{RMB}$, which is 3 times as high as in USA, and 5 times as high as Japan. In the industrialized part of China a special tariff could be added to each kWh of energy when the reserve capacity is lower than a certain threshold, say $5 \%$. The smaller the reserve capacity, the higher the special tariff. If there is no spare and curtailment of load becomes inevitable, the tariff would be still higher. This measure would encourage all users to save their energy, and this tariff can be used for building new power plants.

8) Economic signaling in power market design. To encourage incentive of investment for building new power plants and transmission lines, Long Term Marginal Cost (LTMC) combined with MW-KM price system is proposed that would give an economic signal for investors to select the best site to build new power plants. And it is proposed to use a twopart transmission service charge system, including a fixed charge to compensate the investment charge, and an operation charge to cover the operation charge. This system would encourage the incentive of investors to build new transmission lines.

9) Implementation of more sustainable new energy source. For instance, in summer time the air conditioning load becomes very high. In Central China, the air conditional load reached $30 \%$ in summer of 2003. If solar energy generators are encouraged to be installed on top of all new buildings, it can be best utilized to feed air conditioning load, because the hotter the weather, the more power can be generated by solar generators. In the winter, solar energy can be also be utilized for heating purposes.

Thus, China's economic growth rate has been very fast. The average rate of growth from 1978-2000 was $9.5 \%$. But the average rate of growth of total installed generation capacity was only $7.8 \%$, which was the main cause for energy shortage. Lack of investment was the limiting factor for installing more generation plants and transmission lines.

China started her deragulation in late nineteen nineties. six provincial power markets were in trial operation in 1999-2000. Restructure of Chinese power sector was completed in 2003. five large generation companies and six regional grid companies were formed. NE China Grid Company was the first regional power market in China, it is characterized as a sole wholesale power market in the region. The second regional power market is East China, it is characterized as a hierarchical power market, where provincial power markets would coexist with the regional power market. Other regional power markets will fall into either NE mode or East China mode.

Past generation planning and transmission expansion plan procedures in China have been presented. Investment for expansion usually comes from various sources. Future procedures for generation and transmission planning and investment have been discussed. By installing more generation and transmission lines and limiting investment for energy intensive industries and by implementation of various demand elasticity measures, the energy shortage problems were alleviated by 2005-2006. 


\subsection{Generation Planning and Investment under Deregulated Environment: Comparison of USA and China}

Since the 1980s, the electricity supply industry in the west and in South America has been undergoing rapid and irreversible change reshaping an industry that for a long time has been remarkably stable and had served the public well. A significant feature of these changes is to allow for competition among generators and to create market conditions in the industry, which are deemed necessary to reduce costs of energy production and distribution, eliminate certain inefficiencies, shed manpower and increase customer choice. While such restructuring also started in China several years ago, the situation is very much different from that in the west and other countries. As a result, a modified form of restructuring is occurring in China, driven by a need for rapid expansion of capacity in all three sectors, i.e. generation, transmission and distribution.

The power industry in China has rapidly developed in the past 25 years, and currently the generation installed capacity in China ranks the second in the world, only next to USA. Even so, the capacity is still not enough since the economics expand very fast. The annual electricity demand growth rate is around $15 \%-20 \%$ in the recent 3 years. In the summer of 2003, nineteen provinces suffered electricity supply shortage, accounting for two-thirds of the provinces in China.

The power industry in China will keep a rapid development in the next 20 years. The total annual power consumption will be 2,700 TWh by 2010, and the total installed capacity in China will be 600GW then. The annual increase of power consumption will be $4.5 \sim 5.5 \%$ from 2010 to 2020, the total power consumption will be 4,200 4,600 TWh in China by 2020, and the total installed capacity in China will be 900GW then. With the projects being completed, such as the "Power transmission from the west to the east", the "Mutual transmission power between the north and the south" and the "Inter-connection of power grids over whole China", there will be a nationwide power grid in China.

While the power industry restructuring represents a world-wide trend and the Chinese government has already decided to reform the power industry by separating the generation sector from the transmission/distribution sectors, there exist extensive debates concerning how competition and sustainable development of the power industry in China could be well balanced.

In fact, one of the key issues in restructuring of the power industry is to ensure that an adequate generating capacity will be available for reliable supply. Without sufficient supply, there will be no competition, and hence, the market will not work properly. This problem appears more serious in China since the load demand increases rapidly [15-17].

\subsubsection{Reforming History of the Power Industry in China}

The power industry in China used to be governed by the former Ministry of Electric Power with combined functions of regulation and enterprise practice before 1985. Due to rapid development of economy and hence increasing demand of electric power, electricity shortage became a very serious problem. However, at that time the government did not have much money to build power plants. To solve the problem, investment for power plants 
from different sources was encouraged by the government. To attract generation investment, the government guaranteed the recovery of generation investment and reasonable return. Specifically, there was a very stimulating mechanism for investment in generation plants at that time. For each IPP, the amount of electricity generated every year and the tariff associated were ensured by a long-term agreement signed by the governments. In general, the yearly return on investment was over $15 \%$. With such a high and stable return and without investment risk, more and more capital was raised for the power generation sector, and as a result, a large number of independent power plants (IPP) have been built in China in the past 15 years.

In order to separate administrative functions from enterprises, the State Power Company of China (SPC) was established in 1997. It inherited from the former Ministry of Electric Power all the assets of power networks and around $50 \%$ of the generation installed capacity. By the end of 2001, SP had a total capital of $1,002.7$ billion RMB, accounting for $72 \%$ of the total capital of China's power industry and ranking the sixtieth among the world 500 strongest enterprises.

In 2002, a significant reform with far-reaching influence was initiated for the power industry in China. The major objective of this round of reform is to make a break to the vertically integrated monopoly of the power industry, to introduce a market mechanism by organization restructuring, and to establish a regulatory system for the competitive electricity market.

For this purpose, it is necessary to split the assets of the SPC by separating power grids from power generation and the generation companies thus established. They must compete for supplying power in a competitive market. Five national generation group companies and two power grid companies were established at the end of 2003, by following fundamental principles: for each generation group company, the scale of assets and quality of installed capacity must be similar so that competition will be workable. With a rational geological distribution, they all have in principal a share of less than $20 \%$ in the regional electricity markets. In order to govern the operation of electricity markets, the State Electricity Regulatory Commission of China was established at the end of 2002. This committee is responsible for working out operating rules for the electricity market, regulating market operation and maintaining a fair competition among generation companies.

At the end of 2002, eleven power group companies were established in China, including two power grid companies - the State Power Grid Company of China and the South China Power Grid Company; five power generation groups companies - China Huaneng Power Company, China Power Investment Company, China Huadian Power Company, China Guodian Power Company, China Datang Power Company; four auxiliary companies China Power Engineering Consultation Company, China Hydropower Engineering Consultation Company, China Water Resources and Hydropower Construction Company, China Gezhouba Company. The South China Power Grid Company is composed of five provincial power grids - Guangxi, Guizhou, Yunnan, Hainan and Guangdong. The State Power Grid Company of China is composed of the rest of regional power grids - North China (including Shandong province), Northeast China (including the east part of Inner 
Mongolia), East China (including Fujian province), Central China (including Sichuan province and Chongqing City) and Northwest.

The present reform is only focused on the generation sector. It is expected that restructuring will be extended to the sectors of transmission, distribution and sales, but at this moment, the future picture is still not clear.

\subsubsection{Generation Investment}

\subsubsection{Generation investment in the traditional power industry}

Before deregulation, it was the responsibility of utility companies to assure that enough generation capacity was available and usually there was a centralized generation planning and investment associated. The traditional approach to this was to build planning capacities based on the forecasted load, loss of load probability (LOLP) calculation and estimates of the value of lost load (VOLL), and allocate the costs of the generation capacity implicitly among consumers. The investment and planning were regulated by the government or the regulator. As a regulated monopoly, investment recovery and reasonable profits for utility companies were guaranteed by the government or the regulator, and as a result, utility companies did not have real risks on generation investment.

\subsubsection{Generation investment in the restructured power industry}

In the restructured power industry, generally there is no central planning for new generation capacity additions and no guarantee is made anymore for recovery of generation investment and return. On the other hand, generation companies do not have any obligation for ensuring sufficient supply of electricity nowadays and in future. Each generation company makes its own independent assessments of the profitability of new generation projects, as for any other industrial investments. Since electricity markets are more akin to oligopoly rather than perfect competition and there exists strong entry barriers, the supply tends to be less than the socially optimal demand. Hence, it is a problem of extensive concern how adequate generation capacity can be secured in the long run under the electricity market environment. The electricity market failure in California has brought this subject to the forefront.

Investment on new generation capacity additions is a commercial and risky activity and is expected to become more prudent under the deregulated electricity market environment. This is because investors are more interested in short-term investment return, and are reluctant to invest generation capacity which requires large investment and long recovery period and has increasing uncertainties on load variation, restructuring policy and market management rules which influence their benefits. Investors are expected to spend a considerable amount of time and effort in analyzing the interaction between investment and the decentralized decisions by participants. In making a generation investment decision, expectations concerning future electricity demand, spot market prices, variations of regulatory policies, as well as the financial status are major considerations. The locations, capacities and timing of new power plants are basically at the generation companies' own discretion although an indicative generation planning may be provided by the regulator to 
guide the investment and planning, as is the case in several South America countries such as Chile, Peru, Bolivia and Argentina.

It is believed by many people especially regulators around the world that energy markets are not mature enough and cannot be entirely relied on for securing a desired system adequacy so that some supporting mechanism is needed, at least in the near future, in order to ensure adequate generation capacity. As a result, in many operating electricity markets there exist different forms of capacity payments for ensuring sufficient supply in shortand/or long-terms. Up to now, there are basically three approaches for capacity payments as detailed below.

1) Capacity Obligation Model: In this model, a capacity obligation is imposed to customers by forcing them, explicitly or implicitly, to sign long-term contracts with power suppliers. The regulators determine the amount of firm capacity that each one of the consumption entities has to buy, as well as the maximum amount that each generator is allowed to sell. In other words, a reserve is imposed on each load entity in proportional to its load. To meet this requirement, the load serving entity must enter into contracts with generation companies or procure its obligation through a 'capacity market' that is operated by an organization like ISO. This model is employed in Northeast of the USA including PJM, NYPP (New York Power Pool) and NEPOOL (New England Pool). In PJM and NEPOOL, capacity obligations are defined for "load serving entities" or participants. This is the recommended method in the standard market design (SMD) in USA.

A main advantage of this method is that system reliability can be assured according to well proved techniques and procedures that have shown to result in reliable system operation. A disadvantage is that some of the benefit of restructuring may be lost. One of the main problems of the traditional power industry is overinvestment since return-on-investment is guaranteed. By using capacity obligations based on forecasts, there is a risk of overinvestment.

2) Administrative Payments for Capacity: In several countries such as Argentina, Chile, Colombia and Spain, administrative payments are employed with an explicit remuneration for the installed capacity as an economic signal intended to augment the volume of installed and available generation. Specifically, additional payment is made for available capacity during hours with high demand to motivate capacity investment.

Generation companies are offered a capacity payment based on their availability no matter if they get dispatched or not. The capacity payments are collected from customers as a prorated uplift similarly to other uplift charges such as the transmission charge.

This method has several major disadvantages:

It is not easy to determine an adequate level of capacity charge for inducing optimal capacity investments. Basically, the administrative payment for capacity is based on the expected cost of lost load, which is difficult to obtain. Overestimating this cost would create artificially inflated demand for capacity and result in high capacity prices, which in turn will lead to overinvestment on capacity. 
A fixed capacity charge does not adapt to a varying balance between supply and demand for capacity.

3) Explicit Capacity Adder Payment Model: In this model the capacity is priced separately from energy and consumers are not required to procure capacity. At the initial operation stage of the England \& Wales $(E \& W)$ electricity market, this approach was employed. In the E\&W market, the capacity payment is set to the value of lost load (VOLL) multiplied by the loss of load probability (LOLP) on half-hourly basis and paid to all available capacity. However, determining an appropriate level of VOLL is very difficult, and in the E\&W market it is administratively managed by the regulator through estimating the annual marginal cost of capacity required to meet expected demand at the required reliability standard. This is included in the uplift which is added to the spot market clearing price as the power purchase price. No matter if a generator is dispatched or not, it will receive the capacity payment. When the reserve is tight, the capacity payment will be very high. As a result, the price is very volatile. In this model, the capacity payment is basically determined administratively.

This approach has been criticized for distorting the market price and for being particularly easy to manipulate. Large generation companies have sufficient incentives to withhold capacity so as to magnify the capacity payment as well as to increase the market clearing price for energy, and such manifestations have been observed.

Since the capacity payment is dependent on the system operating conditions and hence is uncertain in the future, this method may not be able to induce sufficient investment on new capacity.

Another major problem of this method is the reliance of capacity payments and capacity requirement on VOLL. It has been criticized repeatedly that VOLL is administratively set and has no market base. A possible way to get a reasonable VOLL is through demand side bidding. Another problem is with the simplified calculation of LOLP.

Although it is difficult to state which approach is the best since different market models are employed in different places, determination of capacity payments by a market mechanism is generally believed a better way than by an administrative pricing method which can not adequately reveal the value of capacity and may result in overinvestment as is the case in the traditional power industry.

How to fairly allocate capacity costs among market participants is also a key issue to address. In the last two methods introduced above, capacity payments are shared by customers at a flat rate, which is usually determined based on energy usage and maximum capacity required. In the first method, it is determined by auction.

\subsubsection{Generation investment in China}

The California energy crisis makes the Chinese government more prudent in making the restructuring decision-making of the power industry, especially on generation investment issues. Although the generation sector has already been separated from the utilities in 
China, investment and construction of new power plants are still under strict control of the government.

According to current energy situation, Chinese government has worked out a strategy for the development of the China power industry. That is, "to build up three channels in north China, central China and south China for power transmission from west to east, to further restructure the power generation to improve efficiency, to develop hydropower, to construct of mine-mouth coal-fired units, to shut down small capacity units, to properly develop nuclear power, to encourage heat-electricity cogeneration and power generation by waste material and renewable resources.

Recognizing the fact that a huge amount of investment will be required in the next 20 years so as to meet the need of rapid economic development and the disastrous event happened in California in 2000-2001, Chinese government will employ a so-called "two-part tariff" for generation companies. As the name denotes, the two-part tariff includes a capacity price and an electricity price. The capacity price will be determined mainly based on investment and construction costs of new power units, while the electricity price will be "discovered" through a pool-based electricity market or long-term contracts. In order to improve the investment efficiency, it is expected that a uniform capacity price will be applicable to the same kind of generation units, at least in a same region (in different regions, the investment and construction costs for the same kind of units may be different) and the capacity price will only cover part (such as $80 \%$ ) of the AVERAGE investment and construction costs of the same kind of generation units. In this way, the investor will have some degree revenue stability and it will be easier for them to obtain financing for new generation capacity additions. The government hopes that by providing capacity prices for generation units, the recovery of investment and construction costs could be guaranteed to some extent, and as a result, some incentive could be provided for generation investment.

As expected, the "two-part tariff" has suffered strong objections from academics since this does not match with the market mechanism. However, the Chinese government insists that such a policy is very necessary at least at the stage with rapid economic development, since it will be disastrous if serious electricity supply shortage occurs in the future.

According to development plan of the Chinese government, it is estimated that the installation capacities of hydropower, natural gas combined cycle, nuclear power, wind power and coal-fired generation will respectively be $200 \mathrm{GW}, 80 \mathrm{GW}, 38 \mathrm{GW}, 12 \mathrm{GW}$ and 570 GW in 2020.

In China, it has already been determined that the generation planning will be conducted by grid companies although generation investment will be from different sources.

\subsubsection{Risks in Generation Investment}

As already mentioned before, there is actually no investment risk for the utility companies in the traditional power industry. The SMD of USA actually leaves the investment risk to the load service entities (LSEs) since LSEs have capacity obligations. While in China, the "twopart tariff' is actually used to reduce the investment risk of investors. 
However, in any of the above mechanisms the ultimate risks are borne by the customers and/or investors.

Let us have a comparison of the effects of the above three mechanisms from several aspects such as risk distribution, efficiency incentives and economic signals, based on three scenarios:
a) normal level of power supply
b) over-supply
c) under-supply.

\subsubsection{Risk distribution}

The parts bearing higher risk under different supply scenarios with the above three mechanisms are listed in Table 14.7.

\begin{tabular}{llll}
\hline & $\begin{array}{c}\text { Traditional } \\
\text { method }\end{array}$ & $\begin{array}{c}\text { The two-part } \\
\text { tariff in China }\end{array}$ & \multicolumn{1}{c}{$\begin{array}{c}\text { Electricity } \\
\text { market }\end{array}$} \\
\hline Oversupply & Customers & Customers & Investor \\
Normal supply & No & No & No \\
Undersupply & Customers & Customers & Customers \\
\hline
\end{tabular}

Table 14.7. Risk Distribution

From the above comparisons, it can be concluded that the market based approach for generation investment could provide both high efficiency incentives and strong economic signals although investors have to bear higher risk. On the other hand, the approach employed in China through the "two-part tariff" is a mixture of regulation and competition, and a major difficulty associated with this approach is how to well balance regulation and competition and this is more a problem of art rather than science.

\subsubsection{Efficiency incentives}

The efficiency incentives of generation companies (utilities) under different supply scenarios with the above three mechanisms are listed in Table 14.8.

\begin{tabular}{lccc}
\hline & $\begin{array}{c}\text { Traditional } \\
\text { Method }\end{array}$ & $\begin{array}{c}\text { The Two-part } \\
\text { Tariff in China }\end{array}$ & $\begin{array}{c}\text { Electricity } \\
\text { Market }\end{array}$ \\
\hline Oversupply & Low & Medium & High \\
Normal supply & Low & Medium & High \\
Undersupply & Low & Medium & High \\
\hline
\end{tabular}

Table 14.8. Efficiency Incentives

\subsubsection{Economic signals}

The economic signals through electricity tariffs under different supply scenarios with the above three mechanisms are listed in Table 14.9. 


\begin{tabular}{lccc}
\hline & $\begin{array}{c}\text { Traditional } \\
\text { Method }\end{array}$ & $\begin{array}{c}\text { The Two-part } \\
\text { Tariff in China }\end{array}$ & $\begin{array}{c}\text { Electricity } \\
\text { Market }\end{array}$ \\
\hline Oversupply & Weak & Medium & Strong \\
Normal supply & Weak & Medium & Strong \\
Undersupply & Weak & Medium & Strong \\
\hline
\end{tabular}

Table 14.9. Economic Signals

Thus, a reliable and reasonably priced supply of electricity is critical to the functioning of a modern economy and society. To achieve this goal, it is important to secure adequate generation capacity in the long run. Without sufficient supply, a market cannot lead to maximized social welfare, and sometimes even cannot work at all.

As already happened in California, capacity shortage will probably occur in those markets using the energy-only market model. An adequate capacity payment, in one way or another, appears necessary for ensuring the system adequacy. However, it seems that there does not exist a generally applicable so-called "best" method to solve the generation capacity adequacy problem, since a best solution to this problem is related to many factors such as the past, current and future scenarios of the power industry studied, social and economic development status of the country or region concerned. These factors must be well taken into account in designing a workable electricity market.

The balancing of competitive opportunities and regulatory measures is of great strategic importance in the power industry restructuring and should not be overlooked since the power industry is an important national infrastructure whose failure will have severe social and political implications.

\subsection{Investment And Development Problems Of Russia's Power Industry}

The federal law "On electric power industry" adopted in 2003 stipulates the basic principles of the state investment policy in the Russian electric power industry [18]. These principles need to be specified in the form of a system of measures and mechanisms of their implementation. The general structure of such a system is presented in Figure 14. 5. Let us comment on the scheme.

The most important objectives of the state investment policy in the sphere of electric power industry are to build a positive investment image of the country and develop a market investment infrastructure (a share market and bank system). It is necessary to essentially increase the level of state guarantees to investors which is possible only with the appropriate legal framework, stability and predictability of the state policy in electric power industry development, available economic mechanisms for implementation of state guarantees, etc. These are the problems of Federal Assembly and Government of the country and their solution will help essentially decrease the investment risk components.

Another important objective is to create an effective system of investment risk insurance including the so-called market insurance (options call, etc.). The role of the state in this 
context consists in formation of a legal framework for creation of the insurance system that includes economic mechanisms to support it and provide its stability.

The solution of the problems will also be fostered by an increase in the investment attractiveness of power companies, particularly of the generating companies being formed now, which can be achieved by providing financial transparence of their activity, economic stability, predictability and transparence of the management actions, other corporative measures. The role of the state here is also very important, as it should create the required legal framework to regulate the activity of the generating companies and their management. The framework should reflect the economic mechanisms that stimulate the management of the companies to act properly and employ economic sanctions in the case the regulating laws are violated.

Another aspect of the state regulation of market relations in electric power industry is the antimonopoly regulation that is carried out on the basis of the antimonopoly legislation by the Ministry of Antimonopoly Policy.

Elaboration of the state policy on electric power industry development and mechanisms of its implementation is a key problem and the role of the state in solution of this problem should be decisive. The government and, first of all, Ministry of Energy should be in charge for the state policy elaboration. This activity employs the elaboration of state strategies and programs of the electric power industry development that could determine the scale and proportions of the industry development, based on the need of stimulating some energy technologies, solving certain social problems, etc. The mechanisms for implementation of the state policy on the electric power industry development are tax, credit, export-import and other economic mechanisms.

Federal and Regional energy commissions should play an important part in the system of providing investment and development of Russia's electric power industry. Their main objectives are presented in Figure 14.5.

The considered components create the required conditions for investing into the electric power industry and for its development. The electric power industry development and the investments required should be substantiated in the frames of the management system of Russia's electric power industry and UPS development. This system includes:

- UPS and IPS expansion patterns that should be based on the system properties of the object;

- Strategic plans for expansion of electric power companies;

- Plans for commissioning of power facilities and investment programs;

- Programs for provision of shortage-free electric power industry development;

- Monitoring systems of investment programs.

All these lines require a methodology whose creation is an independent problem for further studies. Here let us focus on substantiating the elaboration of the programs to provide only the shortage-free development of the electric power industry. 
The above components of the state policy on attraction of investments into generating facilities of the electric power industry call for a scrutiny. The complexity of their substantiation and implementation may result in inefficient and irrational decisions that will not lead to the desirable results in terms of external investment inflow. Besides under a free market the short-term objectives of the investors, including the generating companies themselves, dominate the long-term ones [19]. All this may lead to the inadmissible decrease in the reserves of generating capacities, generation shortage and, as a result, rise in electricity tariffs. Therefore there is a need for special measures to prevent such situations.

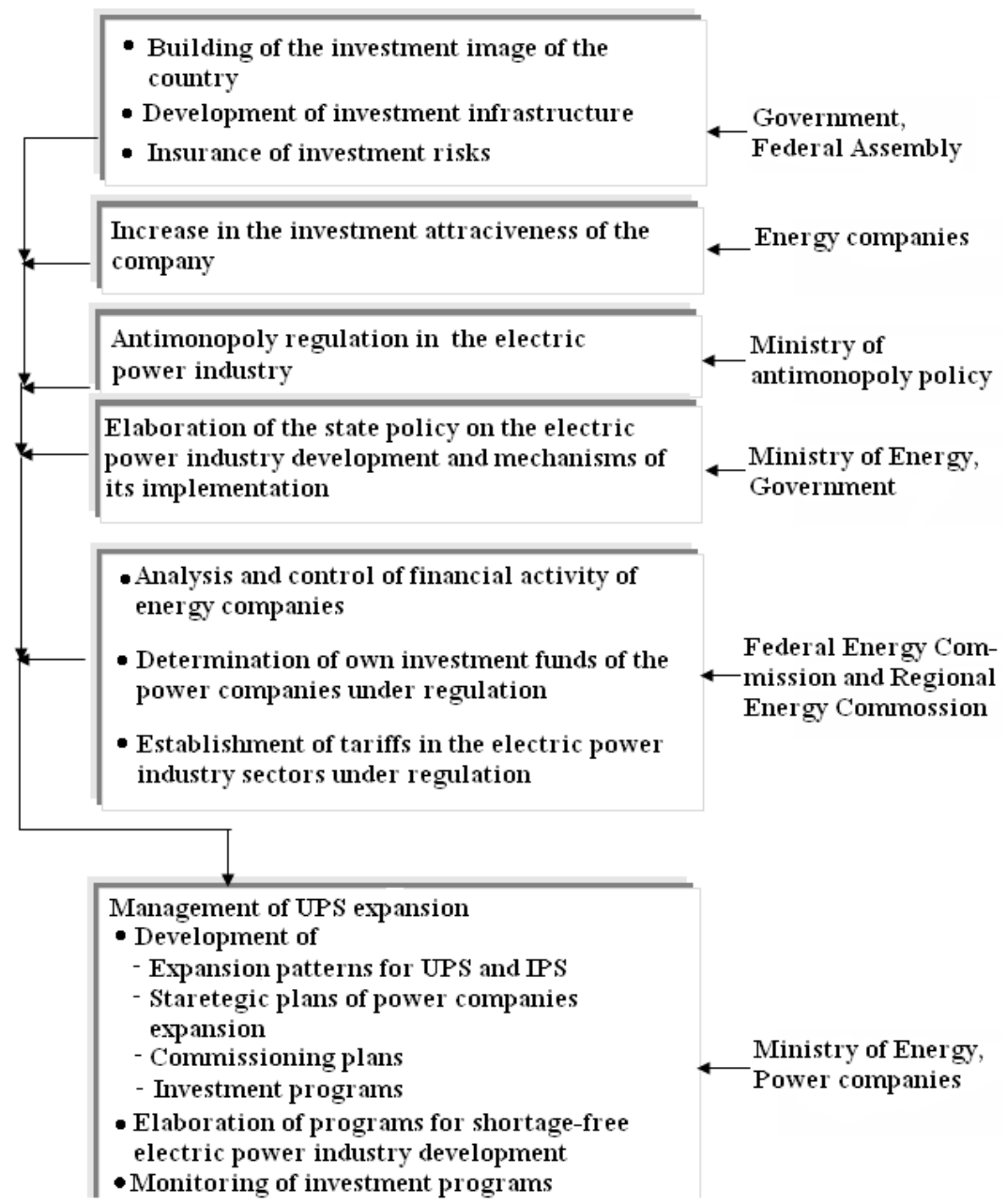

Figure 14.5. Structure of investment attraction and development of Russia's electric power industry 
The federal law "On Electric Power Industry" envisages some short-term and long-term measures on prevention from power shortage and subsequent electricity tariff rise. The short-term measures include introduction of constraints on tariff rise (price caps) and introduction of regulation in the corresponding zone of the wholesale electricity market at generation shortage that may result in disappearance of conditions for competition.

The primary long-term measure in the considered context is creation of the state system of planning the additional generation expansion that could provide permanent availability of surplus generating capacities at the wholesale market and avoidance of their shortage. Nuclear energy that is entirely a property of the state can become a basis for development of such an "insuring" additional generation. Currently the nuclear energy has essential potentialities for commissioning additional generating units. Distributed generation, particularly small gas-turbine co-generation plants, may also play an important role, as there are great potentialities for their construction.

The considered state system of planning the additional generation expansion should form economic mechanisms to stimulate the generating companies and external investors to invest into construction of new power plants. However the main line is creation of the State Foundation for development of energy and energy conservation. Ministry of Energy, Federal Energy Commission and State Construction Committee forwarded the proposal on creation of the Foundation to Russian Government in July 2003.

Creation of the Foundation is particularly topical in 2003-2005 which is related to Russia's electric power restructuring. Further as the market relations grow stronger and the private investors appear the functions of the Foundation can be reduced to provision of system reliability and energy security of Russia.

\subsection{North-East Asia Interconnection Scenario Map, and Power Reserve Strategy in South Korea}

The purpose of this Section is to obtain the reserve power for the future power shortages faced by the metropolitan areas of the Korean Peninsula and by the southeastern area of the South Korea in North-East Asia. The assumed scenarios will be proposed in the cases of without or with connection to the Sinpo nuclear power plant, which is to be constructed with 2,000MW capacity in the future. In this connection, the types of a power transmission for interconnection consist of the 765kV HVAC and the HVDC. In Section 14.8, the various scenarios for providing the interconnection of the power systems among Far-East Russia, North-East China, North Korea, South Korea, and Japan are presented, and the resulting interconnected power systems are simulated by means of a power flow analysis performed with the PSS/E tool. The power flow map is drawn from the data simulated and the comparative study is done.

The interconnection of the power systems among North-East Asian countries (Russia, China, Mongolia, Japan, and Korea) has been proposed on numerous occasions, but little progress has been made due to the complicated political issues and economical problems involved. Now, the necessity for this power system interconnection is increasingly being felt due to the benefit of each country. Because of these reasons, Korea peninsula takes the role 
connect a bridge between different areas of Northeast Asia, such as Russia, Mongolia, China, and Japan. Therefore, the interconnection of the power systems within the Korean peninsula should proceed without delay in order to lay the foundation for a complete interconnection of the various power systems within North-Eastern Asia.

As the substitutes for relieving the problems of power imbalance and the shortage of power in the Seoul metropolitan areas in South Korea and the Pyongyang metropolitan areas in North Korea, five cases of scenarios as follows will be proposed according to the assumed scenario.

- The first case of the scenario involves $765 \mathrm{kV}$ HVAC interconnection between Yangju bus of South Korea and Pyongsan bus of North Korea.

- The second case of the scenario concerns $765 \mathrm{kV}$ HVAC interconnection between the Yangju bus of South Korea and the Pyongsan bus of North Korea to supply the Sinpo nuclear power plant which is to be constructed with 2,000MW capacity in the future.

- The third case of the scenario includes HVDC interconnection between the Busan area in South Korea and the Kyushu area in Japan to solve the power shortage in the Gyeongnam area of South Korea.

- The fourth case of the scenario consists of an HVDC interconnection between Sredne-Uchurskaya HPP in Far-East Russia and Wongi bus in North Korea without supplying Sinpo nuclear power plant in the future,

- In the fifth case of a scenario, the assumed scenario for an HVDC interconnection between Liaoning's power network in North-East China and Supung bus in North Korea will be proposed without supplying Sinpo nuclear power plant in the future.

\subsubsection{Power System in South Korea}

The South Korean electricity generation system can be divided into 7 geographical areas that take geographical boundaries into account. The transmission voltages used are $345 \mathrm{kV}$ for the major networks, and $154 \mathrm{kV}$ or $66 \mathrm{kV}$ for the local systems. Most $66 \mathrm{kV}$ lines are now either being removed or replaced by higher voltage lines. Power system on Jeju Island is now connected to the mainland via a $100 \mathrm{~km}$-long submarine transmission system, comprised of HVDC cables. Because the demand for power is increasing rapidly in the metropolitan area, $765 \mathrm{kV}$ facilities are in the process of being constructed and now come into operation in order to provide a stable large-scale power transmission between the large power generation plants and the areas where the consumers are located. The reasons for upgrading the highest system voltage to $765 \mathrm{kV}$ are to improve distribution between the large power plants and the load centers, to provides a stable supply of electric power, to meet the rapidly increasing demand in the metropolitan area, to resolve the difficulties involving transmission routes and substation sites, to interconnect power plants having a large capacity, and to create the necessary backbone for the transmission system in and around the Metropolitan area. In South Korea, the potential increase in power demand is higher than that of any other country. The metropolitan area situated in the central parts consumed nearly $43 \%$ of the total electricity generated, and the southeast area consumed about $33 \%$. However, most of the large-scale power plants have been constructed in the southern part of South Korea. 
Consequently, the existing power grid includes multiple routes designed to supply the metropolitan area so that, by and large, the direction of power flow is toward the north. The future supply and demand for power is likely to become increasingly unbalanced, because the two regions in South Korea produce a much greater quantity of electricity than they consume. The 5th long-term power supply-demand study published in January 2001 recorded a current total demand of $41,007 \mathrm{MW}$ which will likely increase to $60,718 \mathrm{MW}$ in 2010. The total power generation capacity will have to be increased each year to keep up with the growing demand, and will in fact be raised to 1.5 times the current level for a total of 74,611MW in 2010. It is predicted that the electrical load will attain the level of the current developed countries, sometime between 2020 and 2030, representing a total power consumption of over $80,000 \mathrm{MW}$. This represents doubling of the amount of electricity produced, compared with the present level.

\subsubsection{Power System in North Korea}

This study assumes that the power system in North Korea is divided into 5 areas. The power system in North Korea is smaller than that in South Korea. Most of the hydroelectric power plants are located in the hilly region of the northern areas in North Korea and most of the thermoelectric power plants are located in the metropolitan area. Moreover, power capacity in North Korea has been estimated to be approximately 7,000MW. Currently, it is known that transmission line voltage is composed of $110 \mathrm{kV}$ and $220 \mathrm{kV}$.

\subsubsection{Power System in Far East Russia}

Installed capacity of Sredne-Uchurskaya HPP in Far-East Russia has been estimated to be approximately 3,300MW and average annual output to be about 15TWh. Its total half-wave length is approximately equal to $2,500 \mathrm{~km}$. Interconnection between Sredne-Uchurskaya HPP and South Korea will pass through territories of Far-East Russia, North Korea, and South Korea. The problem of bulk power transport over very long distances of 2,000$4,000 \mathrm{~km}$ can be solved with the help of EHV \& UHV transmission systems in both DC and AC. There are two types of AC transmission systems (TSs) over very long distances, namely line compensation TSs and Half-Wave TSs. The former includes line, terminal substations and reactive power equipment, which are placed at several intermediate substations of line. Power transfer capability of line compensation TS is primarily limited by stability, and the basic function of the reactive power equipment is to secure this. Half-wave line keeps its reactive power balance for all conditions and there is no need to have compensation devices. Transition from double-circuit 2-pole line to single-circuit 4-pole one improves ecological and economical parameters of DC TS at the expense of some increase of risk of forced outage only under extreme contingencies as mentioned above. For traditional AC TS a separate 3-phase line is an independent unit regardless of type of faults (line-to-ground or complete faults).

\subsubsection{Liaoning Region Power System in North-East China}

Liaoning's power network covering the 147,500 square kilometers of land is a modern power network with long history and full of vigor. From 1935 to 1941, the first $154 \mathrm{kV}$ and $220 \mathrm{kV}$ super-grid in China was formed in Liaoning province. This power network owns the first large $220 \mathrm{kV}$-substation (Hushitai Substation) independently designed and constructed 
in China and the first extra-high substation (Dongjia Substation) in China that was independently designed and constructed, and adopted as domestic equipment. It installed the first 25MW fossil-fueled unit in China and the first set of domestic 200MW fossil-fueled units. The $800 \mathrm{MW}$ unit with largest single-machine capacity in China has been put into operation in Suizhong Power Plant. In the province, there are five overlarge thermal power plants with an installed capacity of 1,200MW including Suizhong, Qinghe, Tieling, Jinzhou, and Dalian. Huaneng has four sets of supercritical condensing generating units, and fourteen sets of thermal generating units with single-machine capacity at or above 300MW. Power network of $220 \mathrm{kV}$ has covered nearly all cities above county level and power networks of large cities in the province have formed two rings.

Hydraulic power units may adjust output automatically according to frequency. As a heavy industrial base of China, and with developed politics, economy, and culture, Liaoning province is the power load center in Northeast China. It has one $500 \mathrm{kV}$ line and six $220 \mathrm{kV}$ lines to connect with the power network in Jilin province. It also has two $500 \mathrm{kV}$ lines and one $220 \mathrm{kV}$ line to connect with eastern part of Inner Mongolia. By the end of 2000, the total installed capacity in Liaoning province was 15,185MW (hydropower: 1,156MW; thermal power: $12,559 \mathrm{MW})$. The total installed capacity of the wholly-owned and holding power generation plants of Liaoning Electric Power Co., Ltd. is 2,854MW (hydropower:

456MW; thermal power: $2,398 \mathrm{MW}$ ) and takes up $18.8 \%$ of the total installed capacity of the whole province. The independent power generation company has a total installed capacity of 10,861MW (hydropower: 488MW; thermal power: 10,373MW) and takes up $71.5 \%$. The local self-supply power plants have a total installed capacity of 3,006MW, taking up $19.8 \%$. The installed capacity of the plant at Sino-Korean boundary river is $545 \mathrm{MW}$, taking up $3.6 \%$. In Liaoning province, there are two hundred and one $220 \mathrm{kV}$ lines totaling $7,610 \mathrm{~km}$ and five $500 \mathrm{kV}$ substations with a capacity of 6,000MVA. At present, there are two hundred and one $220 \mathrm{kV}$ lines totaling $7,610 \mathrm{~km}$, and ninety-four $220 \mathrm{kV}$ substations with a capacity of 18,426MVA.

\subsubsection{Power System of Kyushu in Japan}

Japan's power system is divided into nine regional companies serving the areas of Hokkaido, Tohoku, Tokyo, Chubu, Hokuriku, Kansai, Shikoku, Chugoku, and Kyushu, and transmission consists of $500 \mathrm{kV}, 220 \mathrm{kV}, 110 \mathrm{kV}$, and DC250kV lines. The frequency used is $60 \mathrm{~Hz}$ in the western part and $50 \mathrm{~Hz}$ in the eastern part of the country. According to statistics published in 2001, the total generating capacity of the nine power companies is $33,765 \mathrm{MW}$ due to hydropower, $118,112 \mathrm{MW}$ due to thermal power, and $42,300 \mathrm{MW}$ due to nuclear power. The total capacity is therefore 194,177MW. The overhead transmission system consists of $46,692 \mathrm{~km}$ of lines with a voltage of less than $110 \mathrm{kV}$ and $16,048 \mathrm{~km}$ of lines with a voltage of more than $110 \mathrm{kV}$ and $19,324 \mathrm{~km}$ of lines with a voltage of more than $187 \mathrm{kV}$. The total length of these overhead lines is $82,065 \mathrm{~km}$. The underground system consists of $9,333 \mathrm{~km}$ of cable with a voltage of less than $110 \mathrm{kV}, 909 \mathrm{~km}$ of cable with a voltage of more than $110 \mathrm{kV}$, and $624 \mathrm{~km}$ of cable with a voltage of more than $187 \mathrm{kV}$. The total cable length is a $10,865 \mathrm{~km}$. Among these regions, Kyushu has a total land area of $42,163 \mathrm{~km}^{2}$ and is located in the southernmost part of Japan. The generating capacity of Kyushu's Electric Power Company is approximately 30,200MW. The backbone of its transmission system consists of 
$500 \mathrm{kV}, 220 \mathrm{kV}$, and some $110 \mathrm{kV}$ lines. Kyushu's infrastructure is composed of nuclear, thermal, hydro, and geothermal power generating plants. The nuclear power plants are located both in the southwest coastal region and at the furthermost tip of Kyushu's northwest coast. The thermal power plants are located mainly on Kyushu's northeast and the northwest coasts. The hydro power plants are randomly distributed within the north and south central regions. The geothermal power plants are located in the north and south central regions.

\subsubsection{Load Flow Calculations}

Load flow calculations were made for different scenarios:

- Isolated load flow between South Korea and North Korea for North Korea - South Korea - Japan.

- Northward load flow - from South Korea to North Korea.

- Southward load flow - from North Korea to South Korea with Sinpo 2000 MW NPP power injection.

- Northward load flow (from South Korea to North Korea) for Far East Russia - Korea Japan.

- Northward load flow (from South Korea to North Korea for North East China - Korea - Japan.

- Northward load flow (from South Korea to North Korea) after interconnection between South Korea and Japan.

Figure 14.6 shows an isolated flow map for the first scenario as an example of load flow calculations

\subsection{Generation and Transmission Sector in Korean Power Systems}

Throughout the world, restructuring and competition are being introduced into the electric power industry. In Korea, the act on the promotion of restructuring of the electric power industry was approved to allow the division of generation businesses on December 23, 2000. Furthermore, the Electricity Business Act (EBA) was amended in early 2002 so that it could mandate the establishment of an electricity trade market and the advent of a regulatory agency, Korea Electricity Commission. Amongst the radical changes since the restructuring, experiences associated with the investment and expansion planning in generation and transmission sectors is being examined. A long-term generation investment plan, taking into account scheduled and reasonably foreseen unscheduled outages as well as transmission installations is also being considered. Also, the construction, operation, and maintenance of the new facilities will be ensured by a closer examination of development plans for the network. 


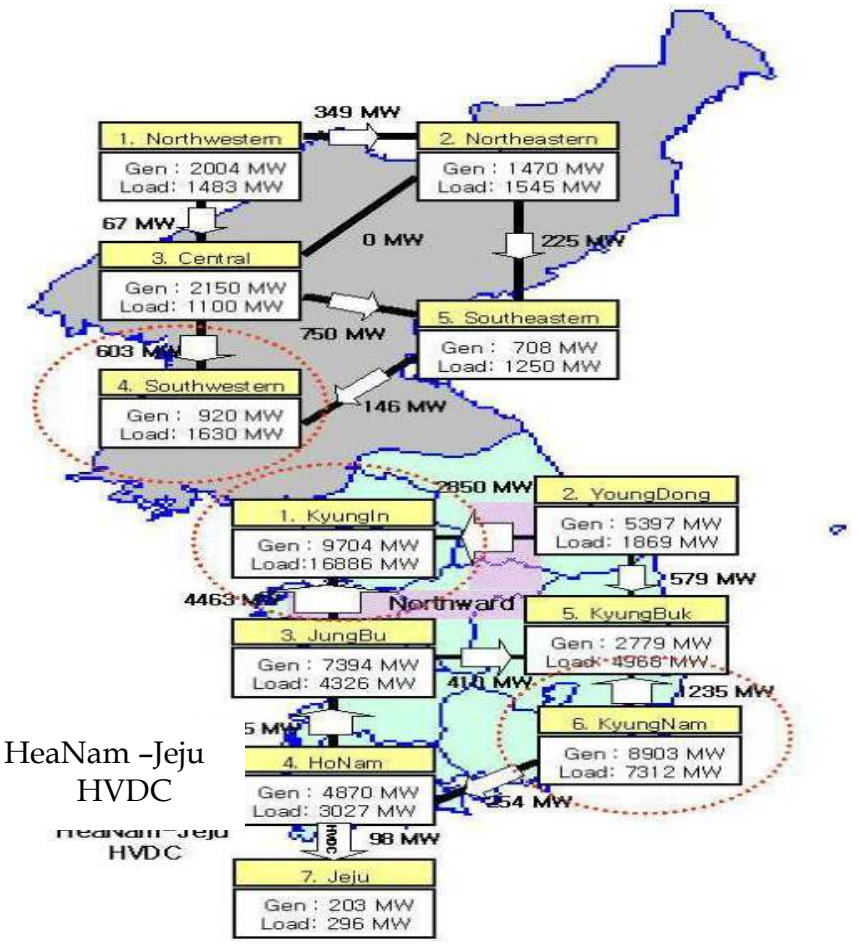

a) Flow in N.K and in S.K.

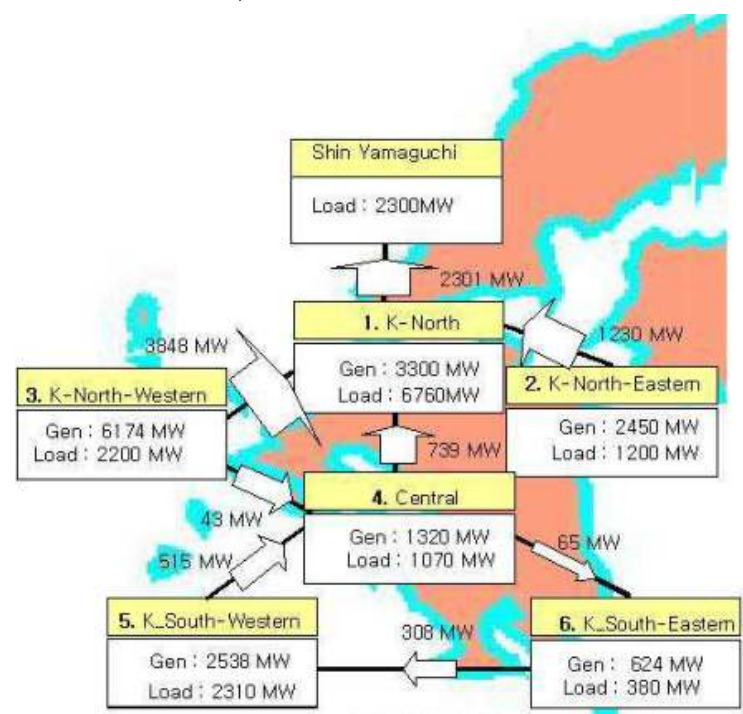

Kyushu region

Figure 14.6. Isolated flow map for N.K-S.K-Japan 


\subsubsection{Generation Sector in Korea}

Before the electricity industry restructuring, the government had established a Long-term Power Development Plan (LPDP) and the Korea Electric Power Corporation (KEPCO), a vertically integrated utility, had implemented this LPDP in order to secure the affordable and reliable electricity supply. Under the domestic requirements and international pressure, the Korean government decided to gradually restructure the electricity supply industry and to promote consumers' rights. With electricity supply industry restructuring, the competitive market mechanism will be the crucial factor. In this context, the function of the former Long-term Power Development Plan inevitably started to make changes into nonbinding guidelines or reference.

\subsubsection{Restructuring plan for electricity industry}

The Korean electricity supply industry restructuring procedures are summarized in the following [20]:

- Generation Competition (2001-2003): Separation and privatization of KEPCO's generation assets into six-generation subsidiaries and the introduction of competition in the generation sector

- Wholesale Competition (2004-2008): Separation and privatization of KEPCO's distribution assets and the introduction of competition in the wholesale electricity supply

- Retail competition (after 2009): Introduction of competition in retail electricity supply.

The Korean government, in consultation with the Korea Power exchange (KPX), biennially sets up the Basic Plan of the Electricity Supply and Demand (BPE) just as it had prepared the Long-term Power Development Plan. Here the KPX in Korea has three major functions [21].

- Facilitates operations of the electricity market by monitoring the process of bidding, metering and performing real-time dispatch to balance the supply and demand

- Ensures stable operations of the electric power system and security of electricity supply including maintaining the stability of transmission networks

- Supports the government in planning strategies to meet the demands for electricity by projecting market trends and forecasting demands for electricity.

However, the BPE will be established not as a binding force but as a tool providing market participants with appropriate information and market-based solutions.

\subsubsection{Investment in generation capacity}

Speaking of the recent electricity supply and demand trend in Korea, the electricity demand has steadily soared in accordance with the nation's high economic growth and the increase in the standard of living over the last 30 years. In 2001, a peak demand of 43,125MW and electricity sales of 258TWh ranked Korea the seventh among the Organization for Economic Cooperation and Development (OECD) members [22], see Tables 14.10 and 14.11. 


\begin{tabular}{ccccc}
\hline Year & 1999 & 2000 & 2001 & 2002 \\
\hline Peak Demand & 37,293 & 41,007 & 43,125 & 45,773 \\
Average Demand & 27,320 & 30,328 & 32,552 & 34,974 \\
Load Factor & $73.3 \%$ & $74.0 \%$ & $75.5 \%$ & $76.4 \%$ \\
\hline
\end{tabular}

Table 14.10. Trend of Demand and Load Factor in Korea (Unit:MW)

\begin{tabular}{ccccc}
\hline Year & 1999 & 2000 & 2001 & 2002 \\
\hline Residential & 34,581 & 37,102 & 39,211 & 42,278 \\
Industrial & 120,859 & 132,260 & 135,791 & 144,454 \\
Commercial & 58,775 & 70,173 & 82,729 & 91,719 \\
Total & 214,215 & 239,535 & 257,731 & 278,451 \\
\hline
\end{tabular}

Table 14.11. Electricity Sales in Korea (Unit: GWh)

In spite of such a high demand growth, the continuous construction of generating plants and the promotion of demand side management have led to a stable electricity supply. Although there was no severe shortage of electricity supply capacity, the Korean electric power system has experienced periodical excesses and shortages of the generating capacity. To overcome this fluctuation, the government offers basic policy directions to the electricity industry including the reliability criteria, optimal fuel-mix, nuclear power plant construction policy, transmission and/or distribution expansion policy, the target of demand side management, and so on.

To sum up the directions of generating capacity construction, the government guides the investors to construct some generating capacity so that the reserve margin and energy resource mix can be satisfied and to adopt advanced generating technologies for additional capacity in order to cope with the strict environmental regulation. It is generally accepted that new generating plants are constructed at the existing sites as much as possible, and yet it is possible for them to be constructed in the vicinity of load centers, taking into the consideration the difficulties in the exploitation of land for transmission facilities.

In the event that the crisis of the electricity supply is predicted mainly due to the lack of generating capacity, the government will be ready to issue a contingency plan including generation capacity addition by the public company. In the near future, the government will reduce the regulatory intervention and organize the institutional foundations so that the electricity market can achieve the goal of the stable electricity supply and demand in the long run.

\subsubsection{Transmission System in Korea}

Improving transmission system operations will go a long way toward easing transmission bottlenecks by delaying or alleviating the need for construction of new transmission facilities. However, construction of new facilities cannot be avoided entirely. We must guarantee that needed facilities are identified in a timely fashion through open processes and that, once identified, they are constructed expeditiously. 


\subsubsection{Overview of current transmission network}

Transmission voltages in Korea are $765 \mathrm{kV}$ and $345 \mathrm{kV}$ for trunk lines and $154 \mathrm{kV}$ or $66 \mathrm{kV}$ for local networks, while the $66 \mathrm{kV}$ lines are being phased out. Also, the power transmission network on Jeju Island is connected to the mainland system by submarine HVDC cables [23] (see Table 14.12).

\begin{tabular}{llcl}
\hline \multirow{2}{*}{ Facilities } & \multicolumn{3}{c}{ Line Length $(\mathrm{C}-\mathrm{km})$} \\
& Overhead & Underground & Total \\
\hline $765 \mathrm{kV}$ & 662 & - & 662 \\
$345 \mathrm{kV}$ & 7,335 & 162 & 7,497 \\
$154 \mathrm{kV}$ & 16,501 & 1,643 & 18,144 \\
$66 \mathrm{kV}$ & 1,398 & 4 & 1,402 \\
$180 \mathrm{kV}(\mathrm{HVDC})$ & 30 & 202 & 232 \\
Total & 25,926 & 2,011 & 27,937 \\
\hline
\end{tabular}

Table 14.12. Transmission Facilities in Korea (as of 2002)

The expansion of the transmission system in Korea will now be focused on.. The voltage levels classify the objectives of the long-term transmission expansion planning:

- 765kV line: It will directly interconnect the generation plants to Seoul metropolitan area.

\subsubsection{Transmission expansion planning}

Several methodologies to improve the performance of transmission facilities are suggested as follows:

- To secure the stability of large-scaled transmission systems: timely expansion of transmission system and transmission voltage upgrades to $765 \mathrm{kV}$

- To develop a countermeasure to the fault currents: strengthening of breaker standards and installation of series reactors

- $\quad$ To balance the supply and demand of reactive power: reinforcement of condensers for electric power, installation of shunt reactors and development of distributed generations.

Most of all, the sizes and date of transmission line construction are determined in such a way that the lines provide sufficient transportation capacity intimately in conjunction with the ultimate generating capacity at the plant sites. Enough has been said to find the authority that would answer the following question: What portion of the construction costs in building up the interconnection lines are charged to generators and/or transmission service providers? Further studies on this issue are needed and discussed in terms of various factors such as voltage level, economic assessment, and technology availability.

\subsection{Acknowledgements}

Nikolai I. Voropai, Professor, Corresponding Member of RAS, Director of Energy Systems Institute, Irkutsk, Russia has prepared and coordinated this Chapter. Contributors include colleagues at the Institute and Members of the IEEE PES W.G. on Asian and Australian Electricity Infrastructure. 


\subsection{References}

[1] Hant, S., Shuttleworth, G., Competition and Choice in Electricity, Chichester, England, A March\&McLennan Co., 1995.

[2] Voropai, N.I., Podkovalnikov, S.V., Trufanov, V.V., "Methodical Principles of Making Decisions on Electric Power System Expansion in Market Environment", IEEE Porto Power Tech. Conf. Proc., Vol. 3, Porto, Portugal, Sept.10-13, 2001.

[3] Voropai, N.I., Ivanova, E.Yu.,"Hierarchical Game Theoretical Problem of Electric Power System Expansion Planning", IEEE Bologna Power Tech Conf. Proc., Bologna, Italy, June 23-26, 2003.

[4] Voropai, N.I., Ivanova, E.Yu., " Multi-Criteria Decision Analysis Technique in Electric Power System Expansion Planning", Electrical Power and Energy Systems, 2001, Vol. 24, No. 1.

[5] Wu, F.F., Contreras, J., "Coalition Formation in Transmission Expansion Planning”, IEEE Trans., Power Systems, 1999, Vol. 14, No. 3.

[6] Chuang, A.S., Wu, F.F., Varaiya, P., “A Game-Theoretic Model for Generation Expansion Planning: Problem Formulation and Numerical Comparison", IEEE Trans. Power Systems, 2001, Vol.16, No. 4.

[7] Voropai, N.I., Ivanova, E.Yu., “A Game Model for Electric Power System Expansion Planning in the Liberalized Environment", MedPower'2002 Conf. Proc., Athens, Greece, Nov. 4-6, 2002.

[8] Kondragunta, J., "Supporting Document for Reliability Criteria for Transmission System Planning", SCE and WSCC Reliability Subcommittee,August 1994.

[9] "NERC/WSCC Planning Standards", NERC, 1997.

[10] "Planning Criteria for Long Term Power System Planning", KEPCO, 1999.

[11] "A Study on Criteria and Standards for Transmission System Planning", KEPCO/KERI, August 2001.

[12] Pandey, M. K., Billinton, R., "Electric Power System Reliability Criteria Determination in a Developing Country", IEEE Trans. Energy Conversion, 2000, Vol.15 No.3.

[13] China Electric Power News, April 13, 2004 (in Chinese).

[14] Wu, F.F., Wen, Fushuan, Duan, Gang: "Generation Planning and Investment under Deregulated Environment: Comparison of USA and China", IEEE PES General Meeting, Denver, USA, June 6-10, 2004.

[15] Yao, J.G., Tang, J., Li, X.Q., Zhang, B.H., "Two Bidding Models of Generation-Side Electricity Market for Application," Journal of Automation of Electric Power Systems, 2003, Vol.27, No.24.

[16] Li, G.H., "Separation of Power Plants From the Grids - A Theme of the Reform in China Power Industry," China Power Investment Group Corporation, Tech. Rep., March 25, 2003.

[17] Wen, F.S., Wu, F.F., Ni, Y.X.. "Generation Capacity Adequacy in the Competitive Electricity Market Environment," accepted for publication by Int. Journal of Electrical Power and Energy Systems, in press.

[18] Federal Law on Electricity of Russian Federation, Draft 202990, February 17, 2003.

[19] Voropai N.I., "Investment and Development of Electric Power Industry in Market Environment", Power Con'2002 Proc., Vol. 1, Kunming, China, October 13-16, 2002.

[20] Ministry of Commerce, Industry, and Energy of Republik of Korea, Basic Plan for Restructuring of the Electricity Supply Industry, January 1999. 
[21] Korea Electric Commission, Restructuring of Electric Power Industry in Korea, July 2002.

[22] Korea Power Exchange, The 1st Basic Plan of Long Term Electricity Supply and Demand, August 2002.

[23] Korea Electric Power Corporation (KEPCO): www.kepco.co.kr. 


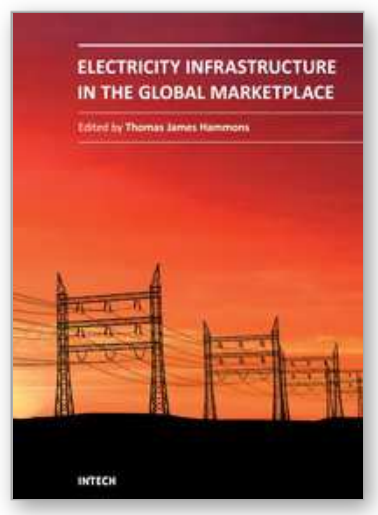

\author{
Electricity Infrastructures in the Global Marketplace \\ Edited by
}

ISBN 978-953-307-155-8

Hard cover, 802 pages

Publisher InTech

Published online 27, June, 2011

Published in print edition June, 2011

This book discusses trends in the energy industries of emerging economies in all continents. It provides the forum for dissemination and exchange of scientific and engineering information on the theoretical generic and applied areas of scientific and engineering knowledge relating to electrical power infrastructure in the global marketplace. It is a timely reference to modern deregulated energy infrastructure: challenges of restructuring electricity markets in emerging economies. The topics deal with nuclear and hydropower worldwide; biomass; energy potential of the oceans; geothermal energy; reliability; wind power; integrating renewable and dispersed electricity into the grid; electricity markets in Africa, Asia, China, Europe, India, Russia, and in South America. In addition the merits of GHG programs and markets on the electrical power industry, market mechanisms and supply adequacy in hydro-dominated countries in Latin America, energy issues under deregulated environments (including insurance issues) and the African Union and new partnerships for Africa's development is considered.

Thomas James Hammons (Fellow IEEE 1996) received the B.Sc. degree in Engineering (1st Class Honors), and the DIC, and Ph.D. degrees from Imperial College, London, UK He is a member of the teaching faculty of the School of Engineering, University of Glasgow, Scotland, UK. He was Professor of Electrical and Computer Engineering at McMaster University, Hamilton, Ontario, Canada in 1978-1979. He is the author/co-author of over 440 scientific articles and papers on electrical power engineering and is Editor of a book on Renewable Energy that was published by INTECH in December 2009. He has lectured extensively in North America, Africa, Asia, and both in Eastern and Western Europe.

Dr Hammons is Past Chair of the United Kingdom and Republic of Ireland (UKRI) Section IEEE and Past Chair of International Practices for Energy Development and Power Generation of IEEE. He is also a Past Chair of the IEEE PES Task Force on harmonizing power-engineering standards worldwide and Past Permanent Secretary of the International Universities Power Engineering Conference. He is a Chartered Engineer (CEng) and a registered European Engineer in the Federation of National Engineering Associations in Europe.

\title{
How to reference
}

In order to correctly reference this scholarly work, feel free to copy and paste the following:

T. J. Hammons (2011). Power Generation and Transmission Expansion Planning Procedures in Asia: Market Environment and Investment Problems, Electricity Infrastructures in the Global Marketplace, (Ed.), ISBN: 978953-307-155-8, InTech, Available from: http://www.intechopen.com/books/electricity-infrastructures-in-theglobal-marketplace/power-generation-and-transmission-expansion-planning-procedures-in-asia-marketenvironment-and-inves 
InTech Europe

University Campus STeP Ri

Slavka Krautzeka 83/A

51000 Rijeka, Croatia

Phone: +385 (51) 770447

Fax: +385 (51) 686166

www.intechopen.com

\section{InTech China}

Unit 405, Office Block, Hotel Equatorial Shanghai

No.65, Yan An Road (West), Shanghai, 200040, China

中国上海市延安西路65号上海国际贵都大饭店办公楼 405 单元

Phone: +86-21-62489820

Fax: +86-21-62489821 
(C) 2011 The Author(s). Licensee IntechOpen. This chapter is distributed under the terms of the Creative Commons Attribution-NonCommercialShareAlike-3.0 License, which permits use, distribution and reproduction for non-commercial purposes, provided the original is properly cited and derivative works building on this content are distributed under the same license. 